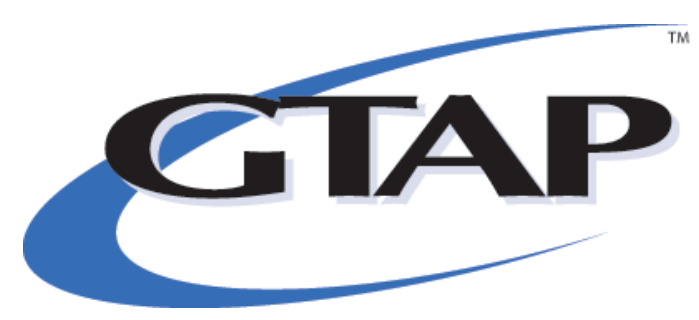

\title{
Disaggregated Data and Trade Policy Analysis: The Value of Linking Partial and General Equilibrium Models ${ }^{1}$
}

\author{
by \\ Badri Narayanan G. * \\ Thomas W. Hertel ${ }^{\dagger}$ \\ J. Mark Horridge $e^{\S}$
}

GTAP Working Paper No. 56

2009

\footnotetext{
${ }^{1}$ The authors are grateful to Prof. Thomas Rutherford, David Laborde, Martina Brockmeier and other seminar participants for their valuable suggestions at $11^{\text {th }}$ Annual Conference on Global Economic Analysis held at Helsinki in June 2008.

* Research Economist, Center for Global Trade Analysis, Purdue University, West Lafayette, Indiana USA, email: Badri@purdue.edu

${ }^{\dagger}$ Distinguished Professor and Executive Director, Center for Global Trade Analysis, Purdue University, West Lafayette, Indiana USA, email: hertel@purdue.edu

$\S$ Professor and Director GEMPACK Software, Centre for Policy Studies, Faculty of Business and Economics, Monash University, Clayton, Australia, email: mark.horridge@buseco.monash.edu.au
} 


\title{
DISAGGREGATED DATA AND TRADE POLICY ANALYSIS: THE VALUE OF LINKING PARTIAL AND GENERAL EQUILIBRIUM MODELS
}

\author{
Badri Narayanan G., Thomas W. Hertel and J. Mark Horridge
}

\begin{abstract}
Computable General Equilibrium (CGE) models are now routinely utilized for the evaluation of trade policy reforms, yet they are typically quite highly aggregated, which limits their usefulness to trade negotiators who are often interested in impacts at the tariff line. On the other hand, Partial Equilibrium (PE) models, which are typically used for analysis at disaggregate levels, deprive the researcher of the benefits of an economy-wide analysis, which is required to examine the overall impact of broad-based trade policy reforms. Therefore, a PE-GE, nested modeling framework has the prospect of offering an ideal tool for trade policy analysis. In this paper, we develop a PE model that captures international trade, domestic consumption and output, using Constant Elasticity of Transformation (CET) and Constant Elasticity of Substitution (CES) structures, market clearing conditions and price linkages, nested within the standard GTAP Model. In particular, we extend the welfare decomposition of Huff and Hertel (2001) to this PE-GE model in order to contrast the sources of welfare gain in PE and GE analyses. To illustrate the usefulness of this model, we examine the contentious issue of tariff liberalization in the Indian auto sector, using PE, GE and PE-GE models. Both the PE and PE-GE models show that the imports of Motorcycles and Automobiles change drastically with both unilateral and bilateral tariff liberalization by India, but the PE model does a poor job predicting the overall size and price level in the industry, post-liberalization. On the other hand, the GE model overestimates substitution between regional suppliers due to "false competition" and underestimates the welfare gain, due to the problem of tariff averaging in the aggregated model. These findings are shown to be robust to wide variation in model parameters. We conclude that the linked model is superior to both the GE and PE counterparts.
\end{abstract}

JEL Codes: C68, F13, F14, F17, O53.

Keywords: CGE modeling, Trade Policy, Partial Equilibrium, India, Auto Industry 


\section{Table of Contents}

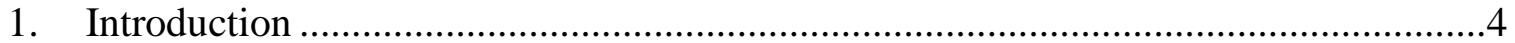

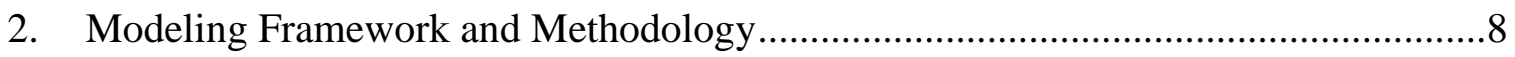



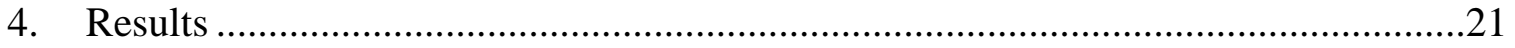

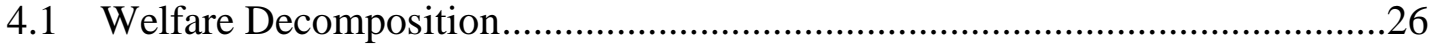

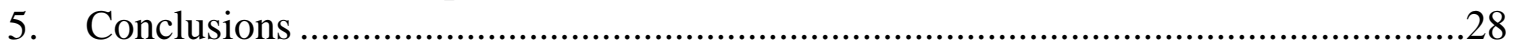



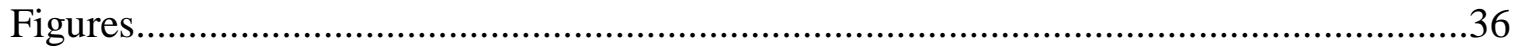

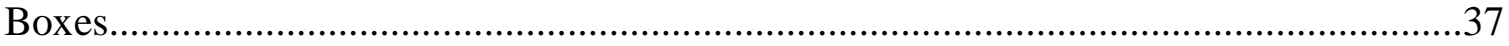






\section{Disaggregated Data and Trade Policy Analysis: The Value of Linking Partial and General Equilibrium Models}

\section{Introduction}

Examination of the impacts of tariff changes at a disaggregated level is important for many reasons.

First, there are huge variations in tariff rates at different tariff lines for many commodities, causing serious aggregation bias in aggregate-sector-based studies. ${ }^{2}$ Second, the aggregation of sectors may result in 'false competition': Two countries that do not compete in a third market at the disaggregated level (e.g., one exports engine blocks and one auto transmissions), may appear as competitors at an aggregate (auto parts) level. ${ }^{3}$ Third, many policies are framed for specific products that are not identified among the relatively aggregated sectors. Finally, most trade policy negotiations are conducted at highly disaggregated "tariff lines", ${ }^{4}$ which is why there has been a strong preference for partial equilibrium (PE) analysis (e.g. Ramos et. al. 2007 and Evans et. al 2007) as negotiations begin to get seriously under way. ${ }^{5}$ As Lloyd and MacLaren (2004) note, the inability to support disaggregate analysis is a major shortcoming of CGE models. On the other hand, while comprehensive PE models may show approximate welfare measures for small exogenous changes (Kokoski and Smith, 1987), they are unable to offer a comprehensive assessment of the impact of trade policy reforms on economy-wide welfare, wages, employment and other variables of interest to

\footnotetext{
${ }^{2}$ Those interested in aggregate impacts can use a specialized technique, such as the Trade Restrictiveness Index (TRI), to account for these differences (eg., Anderson and Neary, 1996), however, the appropriate index will depend on the objective in mind. For example, see Bach and Martin (2001) for an aggregation methodology that factors in expenditure, input costs and tariff-revenue; Anderson and Neary (2003) for Mercantilist TRI (MTRI); and Anderson (2008) for the consequences of atheoretic tariff aggregation in trade policy modeling.

${ }^{3}$ Welsch (2006) finds that intra-industry specialization of the countries over the years leads to the reduction in the heterogeneity of aggregate commodity groups and hence the decline in estimated Armington elasticities.

${ }^{4}$ See Narayanan and Vashisht (2008) for example, for the Free Trade Agreement (FTA) that has been negotiated between India and Thailand. This involves tariff cut proposals at HS-6 level.

${ }^{5}$ Although there have been attempts to model, for example, as many as 500 sectors in a Computable General Equilibrium (CGE) framework by Dixon and Rimmer (2004), they are still far more aggregate than what is required for tariff-line negotiations.
} 
policy makers. These policy indicators are typically produced by Computable General Equilibrium (CGE) models. This paper utilizes a combined PE-GE approach to trade policy analysis, thereby permitting us to contrast the PE, GE and combined PE-GE predictions for bilateral trade flows as well as aggregate welfare and other economy-wide variables of interest.

One of the first attempts to perform a somewhat disaggregated analysis in a CGE framework was made by Basevi $(1966,1968)$. However, there has been a surge in research efforts aimed at linking PE and CGE models only recently. This has been common in the poverty/micro-simulation literature (Herault, 2007; Hertel et. al., 2007b), in sub-regional economic modeling (Madsen and Jensen-Butler, 2004) as well as in the application of econometrics to CGE models (Han and Woodland, 2003; Hertel et. al., 2007a; Bhattarai and Whalley, 1999; Arndt et. al., 2002; and McKitrick, 1998). More recently, authors have begun to link CGE and PE models for disaggregated trade policy analysis. In particular, Grant, Hertel and Rutherford (2007) have proposed a partial/general equilibrium (PE/GE) framework, building on the GTAP-in-GAMS global CGE model (Rutherford and Paltsev, 2000) and focusing on the treatment of tariff rate quotas, which cannot readily be aggregated for use in a normal CGE model. Our paper draws inspiration from this work; likewise implementing a PE/GE model within the GTAP modeling framework (Hertel, 1997).

We focus this paper on determining the impacts of tariff liberalization in India's automotive industry. This is an apt example for several reasons. Firstly, this is a diverse sector, not only structurally, but also in terms of the wide tariff variations across its sub-sectors. ${ }^{6}$ Secondly, India has been actively pursuing different policies for different sub-sectors of the auto industry. ${ }^{7}$ As a

\footnotetext{
${ }^{6}$ See Table 1 for this aspect and Goldberg(1995) for variations in US automobile tariff. The choice of India as an example is further justified by the conclusions of Anderson (2008), which emphasize that the atheoretic aggregation in a multi-country model leads to an overstatement of India's real income by thrice the global gains from free trade. Thus, aggregation is a very important issue in the context of India's tariff analysis, more so for auto sector in particular as explained herein.

${ }^{7}$ For example, most of the tariff policies have been more favorable to the vehicle assembly sub-sector than to the auto-component sub-sector.
} 
consequence there has been policy-driven structural change in the Indian auto industry over the years. ${ }^{8}$ Thirdly, the ongoing tariff negotiations in India are sub-sector-specific, necessitating a framework wherein tariff simulations could be done at sub-sector level.

Since the late 1990s, India has been negotiating trade agreements, covering various sectors, with East and South-East Asian countries, which are both competitors and partners in the global market for autos. ${ }^{9}$ There is a widespread concern that the domestic auto sector is very sensitive to liberalization. ${ }^{10}$ However, the government of India has been cutting auto tariffs, arguing that past tariff cuts have benefitted the industry in terms of better competitiveness, growth and employment (Ministry of Heavy Industries, 2006). So, tariff liberalization in this sector is a contentious issue. Further, the debate over auto sector reforms is relevant in a global context as well, with the potential for India to emerge as a global auto production hub as well as a consumer market. The latter is being fuelled by a rapidly growing middle-class, improved access to finance and a very low vehicle penetration ratio. ${ }^{11}$ Many studies have recently assessed the impacts of FTAs being negotiated by India within a CGE framework (Weerahawa and Meilke, 2007; Kumar and Saini, 2007 and Kawai and Wignaraja, 2007). However, none of them have utilized the kind of PE/GE framework offered by Grant et. al (2007) and developed in this paper.

Using a three-region, ten-sector database derived from the GTAP 6.2 (Dimaranan, 2006), MAcMap (Bouet et. al., 2004) and TASTE (Laborde and Horridge, 2008) databases, we compare the

\footnotetext{
${ }^{8}$ These have, over the years, led to "tariff-escalating" foreign investments, some of which make use of the low tariffs in auto-components sector to largely restrict their production to assembly from imported autocomponents (for example, as Complete Knock Down, i.e., CKD Kits). On the other hand, there are foreign firms that also create domestic capacity in auto-component production. See Narayanan and Vashisht (2008) for more details on this aspect.

${ }^{9}$ Studies such as Iyer (2004) and Batra (2006) examine the prospects of existing agreements involving India, such as the Bangkok Agreement for PTAs in the Asia-Pacific region.

${ }^{10}$ For example, see the consultancy reports such as McKinsey (2005), ICRA (2003, 2004a, 2004b, 2005), which have evaluated the impacts of India's FTA with countries and regions such as ASEAN, MERCOSUR and South Africa.

11 This was around 8.5 cars per thousand Indians in 2005, according to World Development Indicators (2006).
} 
results of complete tariff liberalization in the Indian auto industry, using PE/GE, PE and GE models. We find that in addition to the differences in aggregate results, both the PE and the PE/GE model show strikingly diverse results across the sub-sectors of the auto industry, which cannot be captured by the GE models. However, our simple PE model does a poor job of predicting the changes in the size and price level of the industry. Although this could be improved by building a more complex PE model, that would still not capture economy-wide effect, which is the focus of this study. Thus, we find that the PE/GE model is superior to the GE model in terms of disaggregated impact-evaluation and to the PE model in terms of endogenous determination of aggregate supply and demand. More importantly, the PE/GE model shows lower welfare loss, higher allocative efficiency gains and lower terms of trade losses, because the GE model ignores disaggregated details of trade flows and tariffs.

Apart from being among the first pieces of work developing PE/GE model to perform disaggregate analysis after Grant et. al (2007), this work uniquely contributes to the existing literature in other ways. Firstly, this is the first paper to extend welfare decomposition to the PE/GE framework. Secondly, this implementation is done in the widely-used GTAP framework, thereby aiding this large community of users in performing similar analyses, extending CGE to the tariff-line. Thirdly, our auto industry example effectively shows evidence on issues such as false competition involved in the standard GE model, due to aggregation issues. Finally, the unique comparisons of the results done across the PE, PE/GE and GE models in this exercise highlight the different shortcomings of PE and GE frameworks compared to our proposed PE/GE framework.

This paper is organized as follows: Section 2 outlines the modeling framework and methodology. Section 3 discusses the data sources. Section 4 summarizes the results and Section 5 concludes. 


\section{Modeling Framework and Methodology}

Figure 1 illustrates the quantity and price transmission channels in the PE model. ${ }^{12}$ The PE-GE model developed in this paper is an extension of the standard GTAP Model (Hertel, 1997). ${ }^{13}$ Apart from a few linking equations - which may be neutralized via appropriate use of "slack variables", ${ }^{14}$ it is written as a separate PE "module" appended to the bottom of the GTAP Model code. We follow Grant et. al (2007) in treating production of disaggregated commodities using a Constant Elasticity of Transformation (CET) function, which is conditional on the total activity level in the aggregate sector. We turn now to a discussion of the most important features of the PE model and then explain how this is linked with the standard GTAP Model, resulting in a PE/GE model.

We define the sets DSECT of disaggregated sectors (indexed by $k$ ), ASECT (indexed by $i$ ) of aggregate sectors, (one of which, $D A G G{ }^{15}$ is the aggregation of elements in DSECT and REG ) of regions (indexed by $r$ generally and if the region is the source of exports/imports but by $s$ if the region is destination of exports/imports). We show both the level equations and linearized equations in terms of changes, as they appear in the GTAP Model (Hertel, 1997). Conventions followed for the levels-equations are as follows: ' $P$ ', ' $Q$ ' and ' $\theta$ ', represent different prices, quantities and valueshares, respectively; subscripts/indices $r$ and $s$ denote regions that are sources and destinations, respectively; superscripts $D, O, I M, X M, D D$ and $I D$ indicate domestic demand, output, imports,

\footnotetext{
${ }^{12}$ The unit of measurement for all variables explained in this section is percentage change.

${ }^{13}$ We summarize the standard GTAP model in Appendix 1 . This model has been adapted by many studies such as Tyers and Yang (2004), to suit their particular requirements.

${ }^{14}$ When there are two sets of equations determining the same variable and we want different components of the variable determined by different sets of equations, we may introduce a "slack variable" in one set. When declared endogenous in some components, this variable forces the equation in which it appears, to determine itself. This makes the 'real' variable in question exogenous in the corresponding components. This ensures that the other components of this variable are determined by the other set of equations.

${ }^{15}$ Although the explanations below presume that only one sector is disaggregated using the PE model, for the sake of simplicity in presentation, our framework facilitates any number of sectors in the set DAGG to be disaggregated into any number of sub-sectors, subject to computational constraints, provided we derive a mapping from the set of disaggregated sectors to that of the aggregate ones.
} 
source-destination-wise exports, domestic demand for domestically produced goods and domestic demand for imported goods, respectively. In addition for prices, the superscripts $C I F, M, F O B$ and $D$ represent Carriage-In-Freight, Market, Freight-On-Board and Domestic prices respectively. As for the linearized equations, all the standard GTAP percent change variables of Hertel (1997), pertaining to international trade and margins, enter our model with the same names and a ' $k$ ' suffix to denote disaggregated subsectors. The variables starting with: ' $q$ ' represent changes in quantities, ' $t$ ' represent tax/tariff changes and ' $p$ ' represent changes in prices. For variable names, ' $d$ ' stands for domestic, ' $i$ ' for imports, ' $x$ ' for exports, and ' $o$ ' for output. Box 1 shows the main features of this framework, comparing PE-GE and standard GTAP Models.

\section{a. International Trade}

As shown in equation (1) and Nest C in Figure 1, the CES elasticity of substitution amongst imports from different sources $\sigma_{M k}$, the bi-lateral import prices $P_{k, r, s}^{I M}$ and a calibrated distribution parameter ' $\alpha_{k, r, s}^{I M^{*}}$, distribute the aggregate imports across sources. Further, the import-augmented technology that is specific to the bilateral flow $A M S_{k, r, s}$ affects the level of this trade-flow.

$$
Q_{k, r, s}^{X M}=Q_{k, s}^{I M}\left(\frac{\alpha_{k, r, s}^{I M^{*}}}{P_{k, r, s}^{I M}}\right)^{\sigma_{M k}}\left[\sum_{k}\left(\left(\alpha_{k, r, s}^{I M^{*}}\right)^{\sigma_{M k}}\left(P_{k, r, s}^{I M}\right)^{1-\sigma_{M k}}\right)\right]^{\frac{\sigma_{M k}}{1-\sigma_{M k}}} A M S_{k, r, s}^{\sigma_{M k}}
$$

Equation (2) is the linearized form of (1) above. The percentage change in imports by each region from each of the others is determined by three factors: (i) substitution among different sources, based on the difference between import prices from specific sources to the sum of import-augmented technical change and aggregate import prices $\operatorname{pimk}_{k, s}{ }^{16}$, multiplied by $\sigma_{M k}$, which is the

\footnotetext{
${ }^{16}$ As indicated in equation (1), this is aggregated from $\boldsymbol{p m s}_{\boldsymbol{k}, \boldsymbol{r}, \boldsymbol{s}}$, with the weights as import-shares of different exporters; so, the substitution effect for a particular flow $(k, r, s)$ increases in divergence of import
} 
corresponding elasticity for the aggregated sector as in GTAP 6 Data Base, (ii) import-augmenting technical change, $a_{m s} k_{k, r, s}$, that lowers the effective price of a good in the destination market, and (iii) the import penetration as captured by $q i m k_{k, s}$, the change in composite imports of subsector commodity $k$.

This equation shows the drivers of changes in imports at subsector level. The substitution effects can potentially be lower (or even zero) in a subsector and higher in another than the substitution effect in the aggregate sector. This captures the phenomenon of 'false competition', because there is no competition between two countries in a subsector, but the higher degree of competition in other subsectors will be reflected as a reasonably high degree of competition at the sector level (see Box 3 for an illustration).

$$
\operatorname{qXsk}_{k, r, s}=\operatorname{amsk}_{k, r, s}+\operatorname{qimk}_{k, s}-\sigma_{M k}\left[\operatorname{pmsk}_{k, r, s}-\operatorname{amsk}_{k, r, s}-\operatorname{pim}_{k, s}\right], \forall k \in \text { SSECT; } r, s \in R E G \text { (2) }
$$

This equation may be termed the "PE-counterpart" of the equation that determines $q x s_{i, r, s}$ in the standard GTAP Model. By providing disaggregated predictions of trade volume changes within the aggregate sector, this equation offers an improved estimate of change in bilateral trade flow of good $i$ from region $r$ to $s$. Of course the PE-GE model cannot accommodate two competing predictions of the change in bilateral trade flows, so that the corresponding GE equation must be dropped. This is accomplished via inclusion of a slack variable, qxslack $_{i, r, s}$, in the GE counterpart equation of the standard GTAP Model. When made endogenous, this variable deactivates the standard import sourcing equation. This is the PE-GE closure. In the PE-GE model, aggregate sectoral imports are instead determined by the following aggregation condition, wherein ' $\theta_{k, r, s}^{I M}$ ' is the value for calibrated 
parameter in equation (1), which is the initial share of the value at world prices of a sub-sector's imports in total imports of the corresponding aggregate sector. ${ }^{17}$

$$
q X S_{D A G G, r, s}=\sum_{k \in S S E C T}\left[\theta_{k, r, s}^{I M} q X s k_{k, r, s}\right], \forall r, s \in R E G, \theta_{k, r, s}^{I M}=P_{k, r, s}^{C I F} Q_{k, r, s}^{C I F} / P_{D A G G, r, s}^{C I F} Q_{D A G G, r, s}^{C I F}
$$

Global transport margins are treated in the same manner as in the standard GTAP Model, with the quantity of international trade, transport and insurance services required being proportional to the volume of goods shipped. Technical change in this sector is represented with the variable $a t m f s d k_{k, r, s}$ is obtained by adding up the changes at different levels, which are directly translated from the aggregate changes in the corresponding variables. ${ }^{18}$ As with the global GTAP Model, trade and transport services are provided at a common price, $p t_{r}$, which represents a Cobb-Douglas aggregation of trade and transport services exports from all regions in the model. Deducting the rate of technical progress from this price change gives the percentage change in the commodity and route-specific transport margin, ptransk $_{k, r, s}$.

The price linkages mirror those in the standard model, except for the fact that they are all defined at a disaggregate level and equations similar to (2) are specified to ensure that changes in aggregate imports $\operatorname{qimk}_{k, s}$, aggregate import prices $\operatorname{pimk}_{k, s}$, import tariffs $t m s k_{k, r, s}$, export taxes txsk $_{k, r, s}$, export fob prices ffobk $_{k, r, s}$, import cif prices pcifk $k_{k, r, s}$ and import domestic market prices $\operatorname{pmsk}_{k, r, s}$ add up to the aggregate level. Standard GTAP equations determining each of these variables are de-activated by unique slack variables in a way similar to qxslack $_{i, r, s}$ to facilitate the

\footnotetext{
${ }^{17}$ When the PE only, or GE only, closure is sought, then qxslack $_{i, r, s}$ is made exogenous, and there is no feedback from PE to GE models.

${ }^{18}$ This means that all the shipping-related technical change variables are endogenous in the PE model, as they are directly translated from their exogenous counterparts in the standard GTAP model.
} 
linking of the PE and GE models. Changes in import tariff and export taxes are the crucial policy variables here.

\section{b. Domestic Consumption}

Following Grant et al. (2007), a central point of our specification of consumption (and production see below) is that imports and domestic goods compete at the disaggregated level. This is critical if one wishes to capture the full impact of variation in tariff line data. Hence when we aggregate the disaggregated goods, we are aggregating the import-domestic composite. Local consumption of disaggregated goods $k$ in region $r$ is determined by introducing a CES aggregator function. For this purpose, a new set of variables are introduced in the domestic consumption module: aggregate domestic consumption at both ' $k$ ' (disaggregated) and ' $i$ ' (aggregated) levels $Q_{k, r}^{D}$ and $Q_{D A G G, r}^{D}$, as

well as the associated prices: $P_{k, r}^{D}$ and $P_{D A G G, r}^{D}$. A CES nest (Nest A in Figure 1) with elasticity $\sigma_{k, D A G G}$ is defined as in equation (4), with a calibration distribution parameter ' $\alpha_{k, r}^{D^{*}}$ '.

$Q_{k, r}^{D}=Q_{D A G G, r}^{D}\left(\frac{\alpha_{k, r}^{D^{*}}}{P_{k, r}^{D}}\right)^{\sigma_{k, D A G G}}\left[\sum_{k}\left(\left(\alpha_{k, r}^{D^{*}}\right)^{\sigma_{k, D A G G}}\left(P_{k, r}^{D}\right)^{1-\sigma_{k, D A G G}}\right)\right]^{\frac{\sigma_{k, D A G G}}{1-\sigma_{k, D A G G}}}$

The percentage change in aggregate domestic consumption at both ' $i$ ' (aggregated) and ' $k$ ' (disaggregated) levels are $q d_{i, r}$ and $q d k_{k, r}$, and the associated price changes are $p d_{i, r}$ and $p d k_{k, r}$. Here, the percentage change in the ratio of sub-sector to aggregate sector prices, pre-multiplied by the elasticity of substitution in consumption, $\sigma_{k, D A G G}$, determines the substitution effect, which is augmented by the general expansion effect of a change in the consumption of the aggregate good:

$q d k_{k, r}=q d_{D A G G, r}-\sigma_{k, D A G G}\left[p d k_{k, r}-p d_{D A G G, r}\right], \forall k \in D S E C T ; r \in R E G$ 
Prices at the aggregate level are based on CES indices of disaggregate prices. In percentage change form, we have equation (6) which weights the disaggregated price changes by $\theta_{k, r}^{D}$, the value for the calibrated parameter : the initial share of sub-sector-level value of demand for both domestically and produced and imported goods in aggregate sector-level value.

$$
p d_{D A G G, r}=\sum_{k \in D S E C T}\left[\theta_{k, r}^{D} p d k_{k, r}\right], \forall r \in R E G, \theta_{k, r}^{D}=P_{k, r}^{D} Q_{k, r}^{D} / P_{D A G G, r}^{D} Q_{D A G G, r}^{D}
$$

\section{c. Domestic Production}

This sub-module nests domestic sub-sector-level production within aggregate sector-level production, with a CET elasticity $\varepsilon_{O, D A G G}$ and the calibrated transformation parameter ' $\alpha_{k, r}^{O *}$, as shown in (7) below and in Nest D in Figure 1. This is the production counterpart of (4).

$$
Q_{k, r}^{O}=Q_{D A G G, r}^{O}\left(\frac{\alpha_{k, r}^{O *}}{P_{k, r}^{O}}\right)^{\varepsilon_{O, D A G G}}\left[\sum_{k}\left(\left(\alpha_{k, r}^{O *}\right)^{\varepsilon_{O, D A G G}}\left(P_{k, r}^{O}\right)^{1+\varepsilon_{O, D A G G}}\right)\right]^{\frac{\varepsilon_{O, D A G G}}{1+\varepsilon_{O, D A G G}}}
$$

In linearized form, we can see the relative changes in market prices of composite $\left(p m_{i, r}\right)$ and disaggregated $\left(p m k_{k, r}\right)$ goods determining the supply response, $q o k_{k, r}$, conditional on aggregate capacity in the industry, $\quad{ }^{9 o_{D A G G}, r}$ and the parameter, which is calibrated to the initial share of subsector-level output in total output in the sector that is being disaggregated $\theta_{k, r}^{O}$, as shown in equation (8) and (9), wherein the sub-sector-level price changes are aggregated to sector-level.

$$
\begin{aligned}
& q o k_{k, r,}=q O_{D A G G, r}+\varepsilon_{O, D A G G}\left[p m_{D A G G, r}-p m k_{k, r}\right], \forall k \in D S E C T ; r \in R E G \\
& p m_{D A G G, r}=\sum_{k \in D S E C T}\left[\theta_{k, r}^{O} p m k_{k, r}\right], \forall r \in R E G, \theta_{k, r}^{O}=P_{k, r}^{M} Q_{k, r}^{O} / P_{D A G G, r}^{M} Q_{D A G G, r}^{O}(9)
\end{aligned}
$$




\section{d. Links between Production, Consumption and International Trade:}

The sub-modules explained above are linked with each other. For non-export use, the CES elasticity between domestic and import goods is $\sigma_{D, k}$. Equation (10) shows how local demands for domestic $\left(Q_{k, s}^{D D}\right)$ and for imported goods $\left(Q_{k, s}^{I D}\right)$ are determined by their calibrated distribution parameters $\left(\alpha_{k, s}^{D D^{*}}\right.$ and $\left.\alpha_{k, s}^{I D^{*}}\right)$, prices $\left(P_{k, s}^{D D}\right.$ and $\left.P_{k, s}^{I D}\right)$ and the CES elasticity (Nest B in Figure 1).

$$
Q_{k, s}^{i D}=Q_{k, s}^{D}\left(\frac{\alpha_{k, s}^{i D^{*}}}{P_{k, s}^{i D}}\right)^{\sigma_{D K}}\left[\left(\alpha_{k, s}^{D D^{*}}\right)^{\sigma_{D k}}\left(P_{k, s}^{D D}\right)^{1-\sigma_{D k}}+\left(\alpha_{k, s}^{I D^{*}}\right)^{\sigma_{D k}}\left(P_{k, s}^{I D}\right)^{1-\sigma_{D k}}\right]^{\sigma_{D k}} 1-\sigma_{D k} ; i=D, I
$$

In terms of linearized equations (11) and (12), we can see that the percentage change in sub-sectorlevel domestic consumption, $q d m k_{k, s}$, with corresponding price change $p m k_{k, s}$, substitutes for imported subsector goods, $q i m k_{k, s}$, with corresponding price change $\operatorname{pimk}_{k, s}$. This substitution takes place based on their respective price differentials from the sub-sector-level domestic prices $p d k_{k, s}$. Domestic market and import price changes are aggregated to domestic price changes by weighting according to their respective shares, as shown in equation (13). $\theta_{k, s}^{D D}$ and $\theta_{k, s}^{I D}$ are the calibrated values of the parameters in equation (10), which are value shares of domestic and imports respectively in total local consumption.

$$
\begin{aligned}
& \forall k \in D S E C T ; s \in R E G: \\
& q \operatorname{qimk}_{k, s}=q d k_{k, s}-\sigma_{D, k}\left[\operatorname{pimk}_{k, s}-p d k_{k, s}\right] \\
& q d m k_{k, s}=q d k_{k, s}-\sigma_{D, k}\left[p m k_{k, s}-p d k_{k, s}\right] \\
& p d k_{k, s}=\theta_{k, s}^{D D} p m k_{k, s}+\theta_{k, s}^{I D} p i m k_{k, s}
\end{aligned}
$$


Finally, the market clearing condition is defined as in equation (14). Total value of output is equalized with total value of domestic consumption and exports, with a slack variable. ${ }^{19}$

$$
Q_{k, r}^{O}=\underbrace{Q_{k, r}^{D}}_{\text {DOMESTIC }}+\underbrace{\sum_{s} Q_{k, r, s}^{X M}}_{\text {EXPORT }}+\text { TRADESLACK } K_{k, r}
$$

In linearized form shown in equation (15), the percentage change in total output $q o k_{k, r}$ is equated with the share-weighted sum of exports and domestic consumption for all sub-sectors $k$ and regions $r$. Here, $\theta_{k, r}^{D O}$ represents the share of local consumption in output and $\theta_{k, r, s}^{X O}$ denotes the share of exports to the region $s$ in the total output of region $r$. When the slack variable tradslack $k_{k, r}$ is exogenized, this equilibrium condition determines the change in market prices, $p m k_{k, r}$ and that in output, $q^{\circ} k_{k, r}$, is determined by equation (8).

$$
\begin{aligned}
& \text { qok }_{k, r}=\theta_{k, r}^{D O} \text { qdmk }_{k, r}+\sum_{s \in R E G}\left[\theta_{k, r, s}^{X O} \text { qXsk }_{k, r, s}\right]+\text { tradslack }_{k, r}, \forall k \in \text { DSECT; } r \in R E G ; \\
& \theta_{k, r, s}^{X O}=P_{k, r, s}^{M} Q_{k, r, s}^{X M} / P_{k, r}^{M} Q_{k, r}^{O} ; \theta_{k, r, s}^{D O}=P_{k, r}^{M} Q_{k, r}^{D} / P_{k, r}^{M} Q_{k, r}^{O}
\end{aligned}
$$

It is important to note the difference in closures when the PE module acts independently vis-à-vis when it operates in tandem with the GE model. When this module operates in isolation, we adopt a PE closure in which the aggregate change in industry activity, $q o_{i, r}$ as well as industry demand, $q d_{i, r}$, are fixed. Thus, when $t^{\prime} k_{k, r, s}$ is shocked, owing to the fixation of these quantities, prices adjust in order to maintain the market clearing relationships and equilibria. However, when the PE model is linked with the GE model, $q o_{i, r}$ and $q d_{i, r}$ become endogenous, with the industry expanding in the face of excess profits, and contracting when presented with losses. The response of aggregate demand is governed by the aggregate demand system in the model. Both of these factors will dampen the

\footnotetext{
${ }^{19}$ Note that the values boil down to quantities in equation (14) because all values are in market prices.
} 
degree of price adjustment in the simple PE model. Price adjustment could be controlled in the PE model by introducing structural improvements such as endogenous supply-side features, which are beyond the scope of this paper and we rather focus on economy-wide analysis.

\section{e. PE-GE Linking Features: Slack Variables}

When we integrate the code in the PE model with that in the standard GTAP Model, few endogenous quantity and price change variables in the international trade module are predicted by two equations each. Of course no model can accommodate two competing predictions of these changes, so the corresponding GE equation must be dropped. This is accomplished via inclusion of slack variables in the GE counterpart equations of the standard GTAP Model.

When they are wholly or partly made endogenous, these slack variables deactivate wholly or partly the standard GTAP Model equations for these variables and instead activate the corresponding aggregation equations discussed in this section. Standard GTAP equations determining the variables $q X s_{i, r, s}, \quad p m s_{i, r, s}, \operatorname{pim}_{i, r}, p f o b_{i, r, s}, \quad p c i f_{i, r, s}$ and ptrans $_{i, r, s}$ in the international trade module are deactivated by the unique slack variables, namely, qxsslack ${ }_{i, r, s}$, pmslack $_{i, r, s}$, pimslack inf, $_{\text {, }}$ fobslack $_{i, r, s}$, pcifslack $_{i, r, s}$ and ptranslack $_{i, r, s}$, respectively, to facilitate the linking of the PE and GE models. ${ }^{20}$

\section{f. Welfare decomposition}

We are particularly interested in the welfare impacts of trade policy reform. Beyond suggesting that the PE-GE model shows higher welfare gains, we would like to be able to explain where these gains originate, and track them back to key features of the trade and protection data base. For this reason we extend the welfare decomposition of Huff and Hertel (2001) to encompass the sub-sector flows. This

\footnotetext{
${ }^{20}$ Ideally, these slack variables may be expected to capture the deviations of the PE-GE model results for the changes in corresponding variables, from their counterparts in the standard GTAP model simulations. However, since all these adjustments in different related price and quantity change variables take place simultaneously, they cannot be interpreted in this way. So we do not show them in the results as they are merely used as switch-variables here.
} 
exercise can be seen from equation (16) which shows the decomposition of welfare in the GTAP Model when the only policy intervention is that of tariffs. ${ }^{21}$ In this case, the region-wise equivalent variation $E V_{s}$ is decomposed into the Allocative Efficiency (AE) effect and the Terms of Trade (TOT) effect. These are all pre-multiplied by $\psi_{s}$, a welfare scaling factor with an initial value of one, which changes with the marginal cost of utility as explained in McDougall (2002).

Considering first the AE effect: $\tau$ represents the ad valorem tax and tariff rates, corresponding to the sectors and regions implied by the subscripts and superscripts as mentioned earlier in this section. When the quantity of imports flowing across a given tariff barrier rises, this generates a positive efficiency gain. When it falls, this generates a loss. When a tariff reduction generates a net gain, it is said to be trade-creating, while when it generates a loss, it is trade-diverting. By disaggregating the trade flows in the PE-GE model, we obtain a richer set of interactions between these tariff rates and the associated trade flows, but otherwise the decomposition is unchanged. The terms of trade (TOT) effect for the region $s$ is represented by the second and third terms in this equation. It simply evaluates the change in export prices, relative to import prices, where these are weighted by the associated trade flows. The set NSECT in equation (16) includes all sectors in ASECT except DAGG .

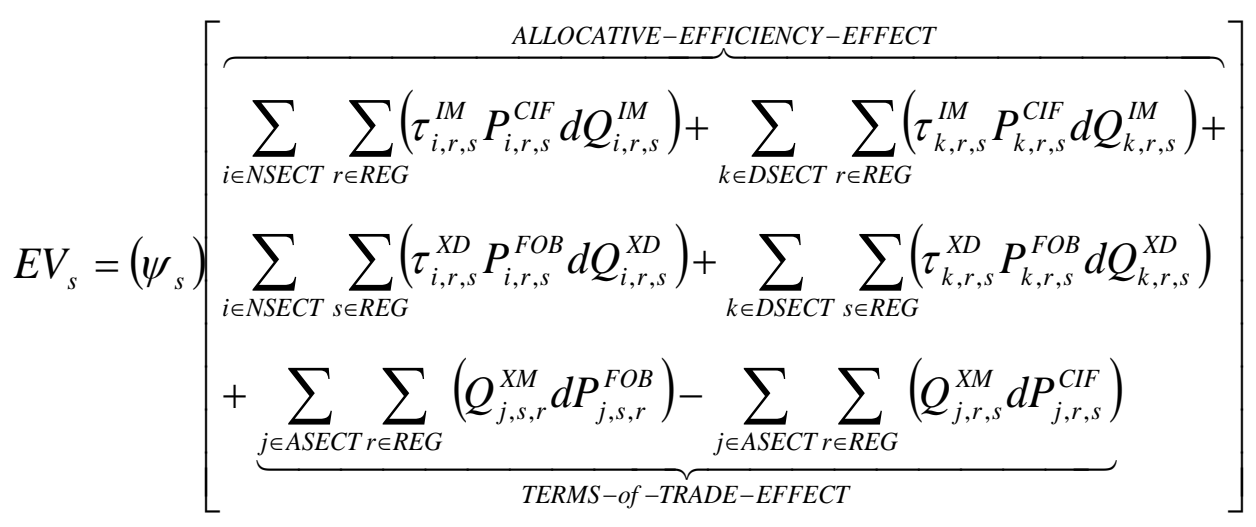

\footnotetext{
${ }^{21}$ We also abstract from the terms-of-trade effect associated with the savings and investment goods in this model.
} 


\section{Data Sources and Description}

GTAP Data Base Version 6.2 is the main source of data used in this study. This is documented in Dimaranan (2006) and covers 57 sectors and 96 regions with base year 2001. For the sake of simplicity, the PE model for the auto sector is broken down to plausible aggregations ${ }^{22}$ of HS-6 level sub-sectors using the new TASTE software package (Horridge and Laborde, 2008), which is based on the MacMAP_2001 data set (Bouët et al., 2004). TASTE also provides the HS6 level data on bi-lateral trade (Value of Imports at cif prices of good $k$ from regions $r$ to $\left.s: V I W S K_{k, r, s}\right)$, tariffs $\left(\operatorname{RTMSK}_{k, r, s}\right)$ and their mappings to GTAP (Version 6.2) sector-level or at an aggregated level mapped to GTAP sectoral level.

Since GTAP currently aggregates motor vehicles and other transport equipment into a single sector, we use the PE model to capture the differential levels of protection across these sub-sectors in the auto industry, disaggregating: Motor Cycles, Motor Cycle Parts, Automobiles other than motorcycles, Engines and other Parts of Automobiles, and finally, Other Transport Equipment. Other aggregated sectors (Other than Auto Industry) in this framework are: Food, Industries that supply Raw Materials to the Auto Industry, Energy Sectors, Manufactures and Services. To keep things simple, there are 3 regions in the model: India (IND), South-East Asian Countries and other Autosector competitors of India: ASEAN member countries, China, Japan and Korea (SEA) and Rest of the World (ROW).

In order to reflect the realities of the auto industry in India, we make suitable assumptions regarding the behavioral elasticities. The Constant Elasticity of Substitution in demand among auto sub-sectors $\sigma_{k, \text { AUTO }}$ is assumed to be 0.5 , since, for example, motor cycle parts rarely substitute for

\footnotetext{
${ }^{22}$ Detailed aggregations and mappings are available from the authors on request.
} 
automobiles, for an end-user - although autos and parts might substitute for one another in a vertically integrated industry, but this has no empirical basis. ${ }^{23}$ The Constant Elasticity of Transformation among the sub-sectors $\varepsilon_{\text {O,АUтO }}$, however, is assumed to be quite high: -2 , because producers can usually transform some equipment and labor from one auto product to another.

Alternatively, $\sigma_{k, \text { AUTO }}$ could be either lower, say zero, or higher as some extent of demand substitutability is plausible across these sub-sectors, driven by diminishing price-differentials between motorcycles and cars, ${ }^{24}$ for example. Similarly for producers, it is also plausible that switching from, say, automobiles production to motorcycles or auto parts is not straight-forward, ${ }^{25}$ which means even a zero-CET ( $\varepsilon_{\text {O,AUTO }}$ ) is a possibility. To identify whether our results are sensitive to varying both these elasticities together or separately, we carry out a Systematic Sensitivity Analysis (SSA) exercise that varies them with all values over a $100 \%$ range, i.e., the CES elasticity $\sigma_{k, \text { AUTO }}$ is varied between 0 and 1 , while the CET elasticity $\varepsilon_{O, \text { AUTO }}$ is varied between -4 and $0 .{ }^{26}$

Elasticity parameters for the CES among imports from different sources $\sigma_{M k}$ estimated by Hertel et. al. (2006) using disaggregated bilateral trade and transport data, and are those used in the current GTAP Data Base (Dimaranan, 2006), due to the lack of data of domestic usage at this level

\footnotetext{
${ }^{23}$ Hertel et. al (2007a) emphasizes on the importance of econometrically estimating the elasticity parameters in assessing Free Trade Agreements using CGE models. Boussard et. al (2006), Gohin (2005) and Willenbockel (2004) show that elasticities are crucial for CGE simulation results. However, estimates are scarce, so here we assume a range of plausible elasticities instead.

${ }^{24}$ Many Indians can afford motorcycles but not cars, but cheaper cars may cause some to switch, as happened when the relatively cheap Maruti-800 car was introduced in the market in the 1990s. With the introduction of world's cheapest car Tata Nano in the near future, this is expected to happen.

${ }^{25}$ See Narayanan and Vashisht (2008) for more details on production structure in different sub-sectors. Although the players in one sub-sector may diversify into production in others, it is somewhat unusual to see a firm shifting its production from one sub-sector to another with its existing plant and infrastructure.

${ }^{26}$ We assume triangular distribution and use Liu quadrature, which solves the model 4 times for each uncertain parameter. See Arndt and Pearson (1998) for more details.
} 
and the consequent difficulty to estimate these elasticities. The elasticity of substitution between domestic and imported goods, $\sigma_{D k}$, is assumed to be one-half as large as the estimates for $\sigma_{M k}$.

In order to build a consistent database, the aggregate tariffs were re-constructed by computing the weighted average of sub-sector-level tariffs from the TASTE database. This also meant revising the corresponding flows in the GTAP Data Base on bi-lateral trade, namely, Imports at domestic market prices $V I M S_{i, r, s}$, Exports at fob Prices $V X W D_{i, r, s}$ and Exports at domestic market prices $V X M D_{i, r, s}$.

In addition, the model requires sub-sector data on total domestic consumption $V D M K_{k, r}$. This was computed at the sub-sector level by assuming the ratio of domestic consumption to imports at the GTAP-level to be preserved at the disaggregate level as well. Similarly, using the disaggregated data on imports at cif prices VIWSK ${ }_{k, r, s}$ and tariffs, we computed the other flows needed for specifying the model (Imports at market prices VIMSK $K_{k, r, s}$, exports at FOB Prices $V X W D K_{k, r, s}$ and exports at market prices $\left.V X M D K_{k, r, s}\right)$. International transport margins at the disaggregated level were computed by using trade-weights (based on disaggregated import flows) to split the margins data from the aggregated GTAP level. A GTAP "Altertax" simulation ${ }^{27}$ is used to target the sector-level tariffs $R T M S_{i, r, s}$ such that the trade-weighted tariffs in auto sub-sectors equal auto sector's aggregate tariff.

The initial level of tariffs and the subsector shares of imports in total imports in the Indian auto industry from the regions SEA and ROW are summarized respectively in the first and the second 2-column panels in Table 1. The last 2-column panel shows the product of subsector import share and

\footnotetext{
${ }^{27}$ Malcolm (1998) explains the detailed procedure involved in an Altertax simulation. This is done to ensure that all the variables are readjusted such that the database remains balanced. We had to do this because the HS6 tariff revenue from CEPII does not add up to GTAP sector-level tariff revenue. Therefore, we alter the GTAP data to agree with the CEPII data.
} 
tariffs at sub-sector-level for SEA and ROW. The sum of elements in each column in this panel gives the weighted tariff in aggregate auto industry in India, for SEA and IND.

An observation from this table is that imports in more protected sub-sectors, namely Motorcycles and Automobiles tend to be smaller in volume. This is natural as larger tariffs result in lower imports and hence lower import shares. This endogeneity of imports with respect to tariffs means that the welfare gains from tariff liberalization will be understated if we conduct our analysis at the aggregated level, using trade-weighted tariffs (example: Young and Magee, 1986; Lai and Zhu, 2004). This problem has been documented extensively in the literature for trade costs and flows in general (Anderson and van Wincoop, 2004; Hillberry, 2002; Pomfret, 1985) and tariffs in particular (Basevi, 1966, 1968; Ray, 1987; Trefler, 1993; Gaston and Trefler, 1994, 1997; Beghin and Kherallah. 1994; Goldberg, 1995; Olarreaga and Soloaga, 1998; Beghin and Fang, 2002). Indeed, the sector-level weighted-average tariffs are much lower than the highest tariffs seen at the sub-sectorlevel. We can see that SEA is the major source of India's imports of Motorcycles, Motorcycle parts and Engines/Parts, while ROW is the major source of Automobiles and OtherTrans imports. However, the aggregated sector-level data shows that only $37 \%$ of India's total auto imports come from SEA and the remaining 63\% come from ROW. This illustrates the richness of detail and comprehension added by the disaggregate data.

\section{Results}

Using the modeling framework explained in Section 3 we carry out a policy experiment using PE, PE-GE and the standard GTAP (GE) Models. The experiment is a simulation that removes all tariffs in India's disaggregated sub-sectors of the Auto industry. Although it is unlikely in reality that India will totally eliminate all its auto tariffs in the near future, there is an active, ongoing debate in India 
about reducing tariffs in this sector. ${ }^{28}$ The simple PE closure assumes $q o_{i, r}$ and $q d_{i, r}$ are exogenous and have no link with the GE model (Box 2). All variables at the aggregate level pertaining to the sectors other than the one being disaggregated, which is autos in this case, are exogenized.

As shown in Box 2, the standard GTAP Model closure determines all quantities and prices endogenously. ${ }^{29}$ In the closure for the PE model linked with the standard GTAP Model (PE-GE), aggregate supply and demand, ( $q o_{i, r}$ and $q d_{i, r}$, respectively) are endogenous. In the PE-GE model, all the slack variables pertaining to the set DAGG, tariff changes at aggregate sectoral level, and all prices, are made endogenous, while tariff changes at sub-sectoral level and other components of slack variables are made exogenous to facilitate the operation of the standard GE model for all aggregate sectors except those in DAGG. The slack variable used in the market clearing conditions is made exogenous both at aggregate ( tradslack $_{i, r}$ ) and disaggregate (tradslackk $k_{k, r}$ ) levels, to facilitate endogenous determination of market prices, in all closures. We now compare results from all the three models. ${ }^{30}$

Table 2 outlines the results pertaining to Equation (2) of Section 3, which determines percentage changes in bilateral imports of sub-sectors as a function of the tariff cuts. In all models, there is a relatively big and positive domestic penetration effect that contributes to increased imports in all sectors and from all regions. In both PE-GE and GE models, the substitution effect is relatively small -- negative for imports from ROW and positive for imports from SEA, implying that India's

\footnotetext{
${ }^{28}$ This is also justified in the literature. For example, Malakellis (1998) shows that tariff reductions that take place without warning have better macro- and structural implications than those take place by steps based on a previously announced schedule. Given this and the current FTA negotiations, even this may perhaps not be an extreme case, at least in the long-run.

${ }^{29}$ This is the closure in which some relevant slack variables, population change, technical change variables, tax/tariff variables and change in output qo for endowment commodities for all regions are made exogenous. See Hertel (1997) for more details.

${ }^{30}$ We use the non-linear Gragg 2-4-6 extrapolation method for the solution, as mentioned in Pearson and Horridge (2005).
} 
imports from ROW are substituted by those from SEA. Imports from ROW increase to a smaller extent than those from SEA, according to all the models.

The reason for this substitution is that initially ROW goods face lower tariffs than those from SEA, as shown in Table 1. As shown in Equation (2), the percentage substitution effect increases with the divergences of applied tariffs across exporters and decreases with import shares. Table 1 shows that the Automobile sub-sector has the highest differential of India's import tariffs, between SEA and ROW. It can also be inferred from Table 1 that SEA's share in India's Automobile imports is low. These observations explain why India’s Automobiles’ imports from SEA are the most influenced by the substitution effect as shown in Table 2. Similarly, owing to the fact that tariff differentials are low and that SEA dominates of India's imports of Motorcycle Parts (Table 1), the substitution effect attributed to rise in SEA's exports of Motorcycle parts to India is the least. Though the tariff differentials are the same for 'OtherTrans', since SEA's share in its total imports by India is lower to begin with, the substitution effect is larger here, for SEA and ROW.

Imports of Motorcycles and Automobiles face a dramatic rise due to the domestic penetration effect, as they both have very high initial tariffs. Even the substitution effects in their imports from SEA and ROW are high, as tariff-differences between imports from SEA and ROW in these subsectors are much higher than those in other sub-sectors. Although the tariff-difference is not so high in the "OtherTrans" sub-sector, this is the biggest import sub-sector within the auto imports from ROW, as shown in Table 1, and hence the substitution effect is higher for this sub-sector, than in the others except Automobiles, for which the initial tariff-difference between SEA and ROW is the biggest among all sub-sectors. 
For Motorcycle Parts, both the domestic penetration effects and the substitution effects are lower in both SEA and ROW, because the tariffs for these regions are not as divergent as in the case of other sub-sectors and their import shares are negligible. Although Engines and Parts constitute sizable shares in auto imports in both regions, the substitution effects are less pronounced than penetration effects due to the relatively low initial tariff differences, similar to those in Motorcycle Parts. Given that import share of this sub-sector in total auto imports from ROW is much lower (about 21\%) than the corresponding share for SEA (about 59\%), it is plausible why this sub-sector has far lower substitution effect than Motorcycle parts in ROW and has far higher substitution effect than Motorcycle parts in SEA.

While the differences in substitution effects among PE and PE-GE models are not significant, ${ }^{31}$ it clearly emerges from Table 2 that the domestic penetration (based on both $q i m k_{k, r}$ and $q i m_{i, r}$ ) levels are considerably lower in almost all of the PE model results. ${ }^{32}$ This follows directly from the main difference between the PE and PE-GE models: the aggregate output and demand are fixed in the PE model, hence limiting adjustment of all quantities, while the endogenous nature of the aggregate output and demand results in more dramatic changes in all quantities in the PE-GE model (Table 3). Domestic and market prices change to a smaller extent in the PE-GE and GE models, because the aggregate supply and demand quantities, which are endogenous in both frameworks, get adjusted to the tariff-shock. This also explains why quantity changes are higher in economy-wide frameworks.

In the GE model, changes in imports from SEA and ROW are more modest than predicted by the sub-sector-level models (Table 2). The reason for this is that most of the sub-sector-level tariffs

\footnotetext{
${ }^{31}$ The only exception for this is the substitution effect in ROW for Other Trans, which is rather higher in PE (-50.3) than in PE-GE (-5.4). Though the adjusted figures for contribution to qxsk are indicative in all other cases, they diverged in this case, as the "implicit" qxsk was about 0.2 , while the actual was about 2 .

${ }^{32}$ In fact, all quantity changes are lower in PE. There is no substitution effect in the PE model at the aggregate level and the aggregate change in imports is merely the import-weighted sum of changes at the sub-sector level.
} 
are far higher than the aggregate tariffs, the only exception being OtherTrans. Similarly, the tariffs are much higher in SEA than in ROW at sub-sector-level, while the differences between these tariffs are not so high for the aggregate auto sector (Table 1). Thus, the differences in tariff cuts arising from the same experiment are much higher in the sub-sectors than in the aggregate auto sector. These are carried forward to other price variables as illustrated in Table 3, resulting in much higher changes in imports, according to the PE/PE-GE models.

Import-penetration effects are slightly higher in the PE-GE model than in the GE model. However, the substitution effect is far lower in the PE-GE model for imports from SEA. This is because of the fact that there is 'false competition' in the simple GE model. Specifically, SEA exports mainly Engines and Parts to India, whereas ROW exports Other Transport Equipment, but at the aggregate level the only information available is that ROW is a bigger exporter than SEA (Table 1), which means higher contribution of substitution effect to changes in imports from SEA in the GE model than in the PE-GE model, wherein the import changes are the aggregations from sub-sector level results explained above. ${ }^{33}$ This phenomenon is explored in more detail in Box 3.

The differences between PE-GE and GE model results arise mainly because the variables pertaining to auto industry in the PE-GE model are aggregations of their counterpart-variables at the sub-sector-level. The import share of ROW in total imports by India is lower than the share of imports from SEA. This, in addition to the lower tariff for imports from ROW, implies lower tariffcuts for imports from ROW, in our scenario of complete tariff liberalization. This results in lower domestic price changes of imports from ROW and hence lower changes in aggregate import prices from ROW in all the results. However, the changes are sharper in the PE-GE model than in the GE

\footnotetext{
${ }^{33}$ The differences between the results in PE-GE and GE models are absorbed in the slack variables in the model. We do not present them in this paper, however, since they do not add much to the inferences, other than what we have already explained in this section, that PE-GE model results are quite different from GE model results.
} 
model, since the much sharper changes at the sub-sector-level are reflected in the aggregated price variables in the PE-GE model.

All these results are found to not be sensitive to the assumed CES or CET elasticities, as shown by the bounds for PE-GE results obtained from the Systematic Sensitivity Analysis (SSA) exercise in Table $3 .^{34}$ For example, imports from SEA change to a lesser extent in the PE-GE model than in the GE model, even when we consider the Upper Bound of this variable in the former (72.5\%), which is lower than $76.7 \%$ as shown in the GE model.

The results for the sub-sectors from both PE-GE and PE models shed light on the fact that the changes in import prices and quantities are much higher for Motorcycles and Automobiles, due to the high tariffs in these sub-sectors. Since the domestic price change is the weighted average of market and import price changes as seen in Equation (13), domestic prices tend to move along with market prices. Given that the domestic shares are very high for all sub-sectors (80-100\%), domestic price changes for all these sub-sectors are derived more from the market price changes than from the import price changes. As in the aggregate auto sector, the PE model shows much steeper decline in all prices at sub-sector level, in order to keep aggregate quantities unchanged.

\subsection{Welfare Decomposition}

One of the great strengths of CGE analysis is the ability to provide an exhaustive accounting of economic welfare. As shown in Table 4, we find that the welfare results in PE-GE (based on equation 16) are considerably different from those in GE at the aggregate level. Comparing the overall welfare results for both these models, we infer that total welfare gain inferred from the PE-GE model is much higher than that inferred from the GE model. All of this can be traced to the Allocative Efficiency (AE) gains. Region-wise welfare changes are entirely explained by AE gains, Terms of Trade (TOT)

\footnotetext{
${ }^{34}$ We do not show the Systematic Sensitivity Analysis results for the PE model because the results in PE are already way different from others and we are more interested in seeing if PE-GE and GE results differ enough.
} 
changes and Investment-Savings (I-S) adjustments. According to the PE-GE model, AE gains are higher for all regions, than those shown by the GE model. In fact, even the lower bounds for AE gains in the PE-GE model results are higher than those in the GE model results. ${ }^{35}$ ROW gains substantially more from TOT changes, India loses more and SEA gains less in the PE-GE model, when compared with the GE model's results. India's greater loss in TOT shown by the PE-GE model is outweighed by its far greater AE gain, resulting in a lower aggregate welfare loss for India. (See Box 4 for an illustration of welfare differences.)

Table 5 summarizes the tax-related $\mathrm{AE}$ effects of welfare changes, focusing on import tax and Indian auto imports, which is the sector directly affected by the tariff cut in this simulation. Understandably in both models, the welfare change is much higher for imports from SEA as the corresponding base import tariff and hence the changes in import volume are much higher than those for the imports from ROW. However, the extent of total welfare gain is also higher in the PE-GE model than in the GE model. Although the changes in imports from SEA are lower in PE-GE than in GE, the welfare change is higher in the former. As for imports from ROW, both change in imports and welfare change are higher in the PE-GE model.

Table 5 also traces back to the sub-sectors to identify why the AE-related welfare gain shows up as higher in the PE-GE model. This is largely because of the sizable welfare gains in three subsectors: Automobiles, Engines and Parts and Other transport Equipments, which have large import shares and base tariff-levels (Table 1) in terms of India's imports from both SEA and ROW, which also means that import tariffs are very high to begin with and vice-versa for other sub-sectors. Owing to the high welfare changes from these sub-sectors, the aggregate welfare change of imports from SEA is higher in the PE-GE model, despite the lower import change. For the imports from ROW, the

\footnotetext{
${ }^{35}$ For example, the minimum AE gain for India predicted by our PE-GE model, with 95\% confidence and varying the assumed elasticities by $100 \%$, is (25.7 Billion US Dollars) is more than twice that predicted by the GE model (11.3 Billion US Dollars).
} 
aggregate welfare change is about twice in the PE-GE model, compared to that in the GE model. All these results are robust to our SSA, as explained in the previous paragraphs and shown in Table 5. Export price changes in Automobiles, Engines and Parts and Other Transport Equipments contribute the most to the TOT effects, to a far greater extent in the PE-GE model. This is largely because FOB prices have adjusted more sharply in PE-GE than in GE, due to the sub-sector-level changes in FOB and market prices.

It is evident from the results in this section that linking the GE with the PE model that has more disaggregated sectors makes an important difference in the results, especially those pertaining to economic welfare. Nesting, price linkages, market-clearing conditions and the GE-linking features in the PE part of the PEGE model do play an important role in defining the results in terms of quantity and price changes and also in eliminating the ills of aggregate analysis such as false competition. Further, all of these findings are qualitatively robust to the values chosen for the crucial elasticities.

\section{Conclusions}

In an attempt to achieve the best of both worlds - specificity to sub-sectors and economy-wide analysis, we find the PE-GE model to be a valuable contribution. With a PE-GE model that incorporates price linkages, CET and CES nests and market clearing equations, in addition to some linking features that provide the much-needed blend with economy-wide treatment, we arrive at much more plausible results than we do using either isolated PE or GE models. (Given the lack of empirical support for the CET and CES elasticities utilized in our PE-GE model, we carried out a Systematic Sensitivity Analysis by varying them and found that all our results are clearly robust to a very broad plausible range of these elasticities.) 
Our PE-GE model is superior to the simple PE model, because it endogenously determines aggregate supply and demand in an economy-wide framework, which is suitable for providing inputs to the real-world trade negotiations. It is also superior to a comparable standard GE model, because it captures structural details at sub-sector-level and gives the modeler a rich set of information related to the impacts of the simulations, at disaggregated sub-sector levels, which is again much closer to realworld situations where the policies are specific to such sub-sectors. Further, even at an aggregate level, PE-GE can yield more realistic results as it is free from the problems arising from working with the aggregate sectors.

As an illustration, our results from complete tariff liberalization in Indian auto industry show two major inferences that further strengthen the evidence for the usefulness of this approach: Firstly, the PE model in isolation shows far lower changes in imports and far higher changes in prices, although it still captures, to a large extent, the disaggregate impacts in sub-sectors. Secondly, the stand-alone GE model shows lower changes in the aggregate imports and does not provide any information about the sub-sectors, which is found to be very crucial in the PE and PE-GE models, in terms of the heavy influx of imports in the automobiles and motorcycles sector from South-East and East Asian economies. Further, the substitution effect appears more pronounced in the GE model, because of 'false competition', as the exporters do not actually compete in the sub-sector-level as much as it appears from the aggregate level.

The GE model shows just the aggregate change which is not very high and may give a misleading signal to the policy-maker that complete tariff liberalization in Indian auto sector may cause significant but not drastic changes. Thus, on both counts, PE-GE model clearly emerges as the preferred framework to address a policy issue that relies much upon the sub-sectors, which also have an economy-wide relevance. 
Furthermore, we extend the welfare decomposition of Huff and Hertel (2001) to the PE/GE model in order to investigate the sources of welfare gain. Comparing the welfare changes with those in the GE model, we find the overall welfare gains to be higher in the PE-GE model. There are many other notable differences, of which we highlight those in the import-tax-related AE effects and the TOT effects. In both cases, all the differences could be traced back to the changes in the disaggregated model that result in different sets of changes in prices and quantities. This further illustrates the usefulness of PE/GE models for policy analysis, as welfare analysis is a very policyrelevant tool offered by CGE models. 


\section{References}

Anderson, J.E. 2008. “Consistent Trade Policy Aggregation”. National Bureau of Economic Research, Working Paper No: 14046, accessible at http://www.nber.org/papers/w14046.pdf.

Anderson, J.E. and J.P. Neary. 2003. “The Mercantilist Index of Trade Policy”. International Economic Review, 44(2): 627-49.

Anderson, J. E. and J.P. Neary. 1996. “A New Approach to Evaluating Trade Policy”. Review of Economic Studies, 63(1): 107-25.

Anderson, J. E. and E. van Wincoop. 2004. "Trade Costs”. Journal of Economic Literature, 42(3): 691-751.

Anderson, J. E. 1998. “Trade Restrictiveness Benchmarks”. The Economic Journal, 108(449): 1111-25.

Arndt, C. and K.R. Pearson (1998) "How to Carry Out Systematic Sensitivity Analysis via Gaussian Quadrature and GEMPACK”. GTAP Technical Paper No. 3, Center for Global Trade Analysis, Purdue University, West Lafayette.

Arndt, C., S. Robinson and F. Tarp. 2002. "Parameter Estimation for a Computable General Equilibrium Model: A Maximum Entropy Approach”. Economic Modelling, 19(3):375-98.

Bach, C.F. and W.Martin, 2001. "Would the right tariff aggregator for policy analysis please stand up?”. Journal of Policy Modelling, 23(6): 621-35.

Basevi, G. 1968. “The Restrictive Effect of the US Tariff and its Welfare Value”. The American EconomicReview, 58(4):840-52.

Basevi, G. 1966. “The United States Tariff Structure: Estimates of Effective Rates of Protection of United States Industries of United States Industries and Industrial Labor”. The Review of Economics and Statistics, 48(2):147-60.

Batra, A. 2006. “Asian Economic Integration”. Working Paper No:186, Indian Council for Research on International Economic Relations, New Delhi.

Beghin, J.C. and M. Kherallah. 1994. "Political Institutions and International Patterns of Agricultural Protection”. The Review of Economics and Statisitics, 76(3):482-9.

Beghin, J.C. and C. Fang. 2002. "Protection and Trade Liberalization under Incomplete Market Integration”. American Journal of Agricultural Economics, 84(3):768-73.

Bhattarai, K. and J. Whalley 1999. "The Role of Labour Demand Elasticities in Tax Incidence Analysis with Heterogeneous Labour”. Empirical Economics, 24(4): 599-619. 
Boussard, J., F. Gerard, M.G. Piketty, M. Ayouz and T. Voituriez. 2006. "Endogenous Risk and Long Run Effects of Liberalization in a Global Analysis Framework”. Economic Modelling, 23(3): 457-75.

Bouët, A., Y. Decreux, L. Fontagne, S. Jean, and D. Laborde. 2004. “The MacMap-HS6 Database: A Consistent Picture of Applied Protection Across the World”. Working Paper 2004-22, Centre d'Etudes Prospectives et d'Informations Internationals CEPII, Paris.

Chadha, R. 2005. Sectoral Study of Automobiles. Report by National Council for Applied Economic Research and Tariff Commission, Government of India, New Delhi.

Dimaranan, B.V., ed. 2006. Global Trade, Assistance, and Production: The GTAP 6 Data Base. Center for Global Trade Analysis, Purdue University, West Lafayette.

Dixon, P.B. and M.T. Rimmer. 2004. “The US Economy from 1992 to 1998: Results from a Detailed CGE Model”. The Economic Record, 80 (Special Issue): S13-S23.

Evans, D., M. Gasiorek and S. Robinson 2007. “A Comparative Analysis of Shallow and Deep Integration of China and India into the Global Economy: A Research Agenda and First Application of the Disaggregated TAPES Partial Equilibrium Model to China”. Paper presented at Tenth Annual Conference on Global Economic Analysis, Center for Global Trade Analysis, Purdue University, West Lafayette, June 7-9.

Francois, J., H. Van Meijl and F. Van Tongeren 2005. “Trade Liberalization in the Doha Development Round”, Economic Policy, April, pp 349-391.

Gaston, N. and D. Trefler. 1997. "The Labour Market Consequences of the Canada-U.S. Free Trade Agreement”. The Canadian Journal of Economics, 30(1):18-41.

_. 1994. “Trade and Wages: Evidence from U.S. Manufacturing”. Industrial and Labor Relations Review, 47(4):574-93.

Gohin, A. (2005). “The Specification of Price and Income Elasticities in Computable Genral Equilibrium Models: An Application of Latent Separability”, Economic Modelling, 22 (5): 205-25.

Goldberg, P.K. 1995. "Product Differentiation and Oligopoly in International Markets: The Case of the U.S. Automobile Industry”. Econometrica, 63(4): 891-951.

Grant, J., T.W. Hertel and T. Rutherford 2007. "Extending General Equilibrium to the Tariff Line: US Dairy in the Doha Development Agenda.” Paper presented at Tenth Annual Conference on Global Economic Analysis, Center for Global Trade Analysis, Purdue University, West Lafayette, June 7-9. 
Han, S. and A.D. Woodland (2003). "An Inter-temporal General Equilibrium Econometric Model for a Small Open Economy with Application to Australia”, The Economic Record, 79(244): 1-19.

Herault, N. (2007). "Trade Liberalisation, Poverty and Inequality in South Africa: A Computable General Equilibrium-Microsimulation Analysis”, The Economic Record, 83(262): 317-28.

Hertel, T.W. (ed.) 1997. Global Trade Analysis: Modeling and Applications. Cambridge University Press.

Hertel, T.W., D. Hummels., M. Ivanic and R. Keeny. 2007a. "How Confident Can We be of CGEbased Assessments of Free Trade Agreements?” Economic Modelling, 24(4): 611-635.

Hertel, T.W., R. Keeny, M. Ivanic and A. Winters. 2007b. "Why is'nt the Doha Development Agenda More Poverty Friendly?” GTAP Working Paper No: 37. Center for Global Trade Analysis, Purdue University, West Lafayette.

Hillberry, R.H. 2002. “Aggregation Bias, Compositional Change and the Border Effect,” The Canadian Journal of Economics, 35(3): 517-30.

Horridge, J.M. and Laborde, D. 2008. "Tariff Analytical and Simulation Tool for Economists: TASTE”, mimeo.

Huff, K. and T.W. Hertel. 2001. "Decomposing Welfare Changes in GTAP.” GTAP Technical Paper No: 05. Center for Global Trade Analysis, Purdue University, West Lafayette.

ICRA. 2003. Report on the Competitiveness of Indian Auto Industry, Society of Indian Automobile Manufacturers, Automotive Component Manufacturers Association of India (ACMA) and Investment Information and Credit Rating Agency of India (ICRA), New Delhi.

ICRA. 2004a. The Thailand \& ASEAN India Free Trade Agreement: Implications for the Indian Auto Industry, Automotive Component Manufacturers Association of India (ACMA) and Investment Information and Credit Rating Agency of India (ICRA), New Delhi.

ICRA. 2004b. The MERCOSUR-India Preferential Trade Agreements -- Implications for the Indian Automotive Industry, Automotive Component Manufacturers Association of India (ACMA) and Investment Information and Credit Rating Agency of India (ICRA), New Delhi.

ICRA. 2005. Implications of an FTA with South Africa for the Indian Auto Industry, Automotive Component Manufacturers Association of India (ACMA) and Investment Information and Credit Rating Agency of India (ICRA), New Delhi.

Iyer, H. 2004. "The Bangkok Agreement: Prospects of Trade Expansion in Asia-Pacific Region” in UNESCAP, ed., Bulletin on Asia-Pacific Perspectives: 2003-04. United Nations Economic and Social Commission for Asia and the Pacific, Bangkok, pp 55-68.

Jensen, H.G. and R. Sandrey. 2006. “A Possible SACU/China Free Trade Agreement: Implications 
for the South African Manufacturing Sector”. Working Paper No. 8/2006, Trade Law Centre for Southern Africa TRALAC, Stellenbosch.

Kawai, M. and G. Wignaraja. 2007. “ASEAN+3 or ASEAN+6: Which Way Forward?”. Discussion Paper No:77, Asian Development Bank Institute , Tokyo.

Kokoski, M.F. and V.K. Smith. 1987. “A General Equilibrium Analysis of Partial-Equilibrium Welfare Measures: The Case of Climate Change”. The American Economic Review, 77(3): 331-41.

Kumar, A.G. and G.K. Saini. 2007. "Economic Co-operation in South Asia: The Dilemma of SAFTA and Beyond”. Working Paper No: 2007-017, Indira Gandhi Institute of Development Research, Mumbai.

Lloyd, P.J. and D. Maclaren. 2004. “Gains and Losses from Regional Trade Agreements: A Survey”, The Economic Record, 88(251): 445-67.

Lai, H. and S.C.Zhu. 2004. "The Determinants of Bilateral Trade”, The Canadian Journal of Economics, 37(2): 459-83.

Madsen, B. and C. Jensen-Butler. 2004. “Thoeretical and Operational Issues in Sub-regional Economic Modelling, Ilustrated Through the Development and Application of the LINE Model”, Economic Modelling, 21(3): 471-508.

Malcolm, G. 1998. “Adjusting Tax Rates in the GTAP Data Base”. GTAP Technical Paper No:12, Center for Global Trade Analysis, Purdue University, West Lafayette.

Malakellis, M. 1998. "Should Tariff Reductions be Announced? An Intertemporal Computable General Equilibrium Analysis”, The Economic Record, 74(225): 121-38.

McDougall, R.M. 2002. “A New Regional Household Demand System for GTAP”. GTAP Technical Paper No:20, Center for Global Trade Analysis, Purdue University, West Lafayette.

McKitrick, R.R. 1998. “The Econometric Critique of CGE Modeling: the Role of Functional Forms”, Economic Modelling, 15(4): 543-73.

McKinsey. 2005. Vision 2015 for the Indian Automotive Components Industry, Automotive Component Manufacturers Association of India (ACMA) and McKinsey and Company, New Delhi.

Ministry of Heavy Industries and Public Enterprises. 2006. Automotive Mission Plan 2006-2016: A Mission for Development of Indian Automotive Industry, New Delhi.

Narayanan, B.G. and P. Vashisht. 2008. "Determinants of Competitiveness of Indian Auto Industry”. Working Paper No: 201, Indian Council for Research on International Economic Relations, New Delhi. 
Olarreaga, M. and I. Soloaga. 1998. “Endogenous Tariff Formation: The Case of Mercosur”. The World Bank Economic Review, 12(2):297-320.

Pearson, K.R. and J.M. Horridge 2005. "Hands-on Computing with RunGTAP and WINGEM to Introduce GTAP and GEMPACK”. GTAP Resource No: 2692. Center for Global Trade Analysis, Purdue University. West Lafayette.

Pearson, K.R., T.W.Hertel and J.M. Horridge. 2005. “AnalyseGE: Software Assisting Modellers in the Analysis of Their Results”. Center for Policy Studies, Monash University, Melbourne.

Pomfret, R. 1985. “Categorical Agregation and International Trade: A Comment”. The Economic Journal, 95(378): 483-5.

Ramos, M.P., J. Bureau and L. Salvatici 2007. "Shipping the Good Beef Out : EU Trade Liberalization to Mercosur Exports”. Working Paper 07/17, The Agricultural Trade Agreements Project (TRADEAG).

Ray, E.J. 1987. “The Impact of Special Interests on Preferential Tariff Concessions by the United States". The Review of Economics and Statistics, 69(2):187-93.

Rutherford, T.F. and S.V. Paltsev. 2000. "GTAPinGAMS and GTAP-EG: Global Datasets for Economic Research and Illustrative Models”, Department of Economics, University of Colorado, September, available at http://www.mpsge.org/papers/gtaptext.pdf.

Trefler, D. “Trade Liberalization and the Theory of Endogenous Protection: An Econometric Study of U.S. Import Policy”. The Journal of Political Economy, 101(1):138-60.

Tyers, R. and Y. Yang 2004. “The Asian Recession and Northern Labour Markets”, The Economic Record, 80(248): 58-75.

Weerahawa, J. and K. Meilke. 2007. "Indo-China Relationships: Implications for the South Asian Economies”. Paper presented at the Symposium of IATRC (International Agricultural Trade Research Consortium), Beijing, July 8-10.

Welsch, H. 2006. “Armington Elasticities and Induced Intra-industry Specialization: The Case of France, 1970-1997”. Economic Modelling, 23(3): 556-67.

Willenbockel, D. 2004. "Specification Choice and Robustness in CGE Trade Policy Analysis with Imperfect Competition”, Economic Modelling, 21(6): 1065-99.

Young, L. and S.P. Magee. 1986. “Endogenous Protection, Factor Returns and Resource Allocation”, The Review of Economic Studies, 53(3): 407-19. 
Figure 1: Illustration of Some Quantity, Price and Volume Linkages in the Model

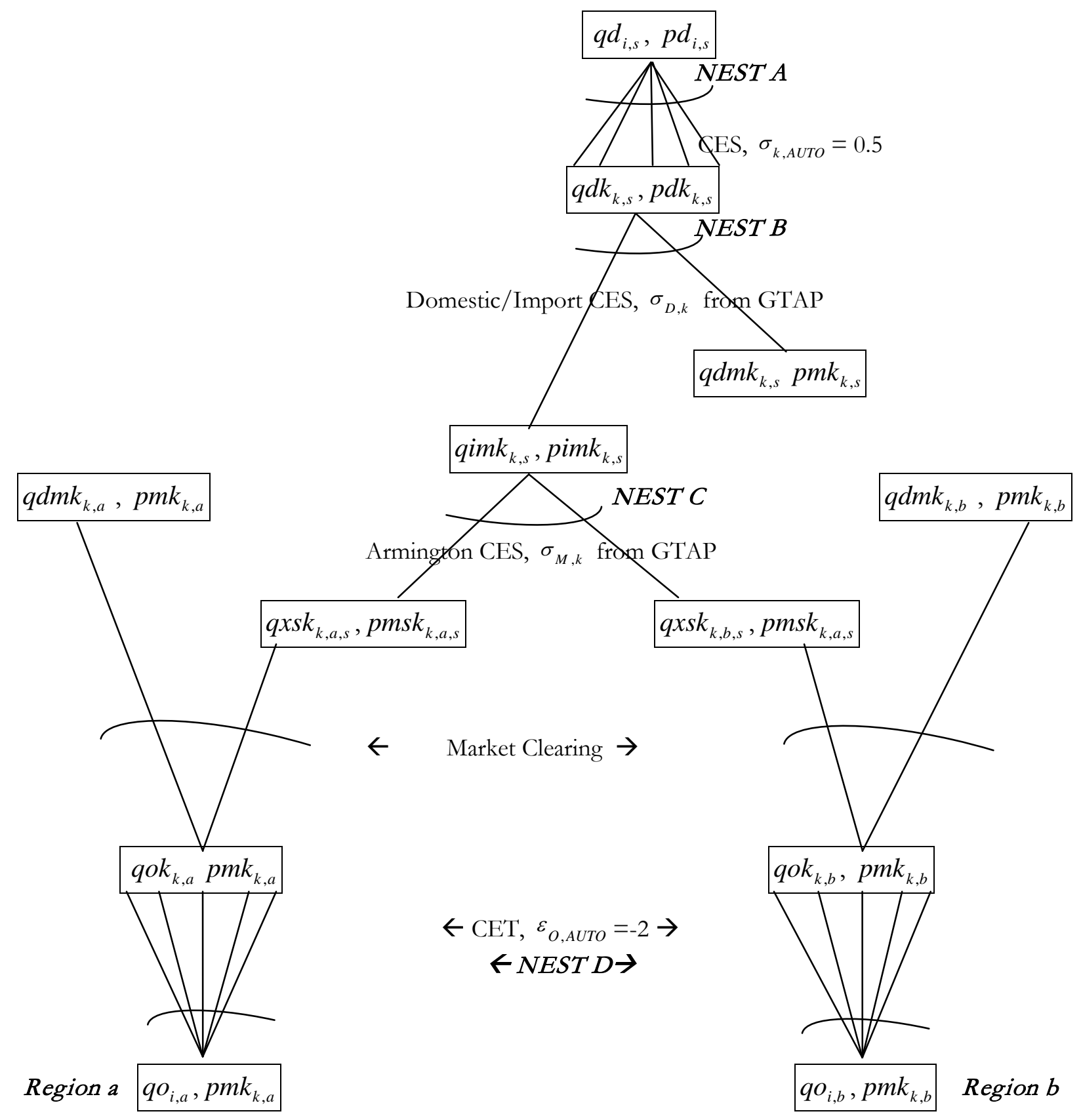


Box 1: Comparison of the Salient Features in Different Models

\begin{tabular}{|l|l|l|}
\hline \multicolumn{1}{|c|}{ Feature } & \multicolumn{1}{|c|}{ Standard GTAP Model } & \multicolumn{1}{c|}{ PE and PE-GE Models } \\
\hline $\begin{array}{l}\text { Substitution among domestic } \\
\text { commodities' consumption } \\
\text { (Nest A in Figure 1) }\end{array}$ & No such feature & $\begin{array}{l}\text { An aggregate user substitutes between } \\
\text { disaggregate commodities }\end{array}$ \\
\hline $\begin{array}{l}\text { Substitution between domestic and } \\
\text { imports } \\
\text { (Nest B in Figure 1) }\end{array}$ & $\begin{array}{l}\text { Each firm and final user } \\
\text { separately substitutes domestic } \\
\text { and imports at sector-level }\end{array}$ & $\begin{array}{l}\text { An aggregate user substitutes domestic and } \\
\text { imports at both sector and sub-sector levels. }\end{array}$ \\
\hline $\begin{array}{l}\text { Substitution between imports from } \\
\text { different sources } \\
\text { (Nest C in Figure 1) }\end{array}$ & $\begin{array}{l}\text { An aggregate user substitutes } \\
\text { imports from different sources } \\
\text { at the sector-level }\end{array}$ & $\begin{array}{l}\text { An aggregate user substitutes imports from } \\
\text { different sources at both sub-sector and sector- } \\
\text { levels. }\end{array}$ \\
\hline $\begin{array}{l}\text { Transformation of domestic } \\
\text { commodities production } \\
\text { (Nest D in Figure 1) }\end{array}$ & $\begin{array}{l}\text { Each domestic firm makes its } \\
\text { own sector-level output }\end{array}$ & $\begin{array}{l}\text { Each domestic firm makes a mixture of sub- } \\
\text { sectors that are transformed from the aggregate } \\
\text { sector-level production }\end{array}$ \\
\hline
\end{tabular}

Box 2: Closures Used in Different Models

\begin{tabular}{|c|c|c|}
\hline PE Model & GE Model & PE-GE Model \\
\hline $\begin{array}{l}\text { Exogenous: } \\
\text { Changes in total output and } \\
\text { demand in all sectors and } \\
\text { regions. } \\
\text { Changes in all price, tax and } \\
\text { quantity variables for non-Auto } \\
\text { sectors at } i \text { level. } \\
\text { Changes in import tax and } \\
\text { import-augmented technical- } \\
\text { change (amsk } k_{k r s} \text { ) variables at } \\
k \text {-level. Slack variable for tradea } \\
\text { market-clearing at } k \text {-level. } \\
\text { Endogenous: } \\
\text { All other price, tax and } \\
\text { quantity changes and slack } \\
\text { variables. }\end{array}$ & \begin{tabular}{l}
\multicolumn{1}{c}{ Exogenous: } \\
Changes in endowment output, \\
price index for primary factors, \\
distribution parameters for \\
savings, government and \\
private consumption and \\
population. \\
Slack variables for consumer \\
goods, endowments, income, \\
profits, savings price and \\
tradeables' market clearing; \\
All technical and tax change \\
variables. \\
Endogenous: \\
All other price and quantity \\
changes and slack variables.
\end{tabular} & $\begin{array}{l}\text { Exogenous: } \\
\text { Changes in endowment output, world price index } \\
\text { for primary factors, distribution parameters for } \\
\text { savings, government and private consumption } \\
\text { and population. } \\
\text { Slack variables for consumer goods, endowments, } \\
\text { income, profits, savings price and tradeables' } \\
\text { market clearing; } \\
\text { Slack variables for different prices, quantities } \\
\text { and welfare-count-variables are exogenous for } \\
\text { non-Auto sectors. } \\
\text { All technical and tax change variables at } i \text { level, } \\
\text { except } t m s_{\text {irs }} t x s_{\text {irs }} \text { tm } t_{\text {ir }} t_{i r} \text { and ams } s_{\text {irs }} \text { that are } \\
\text { exogenous for non-Auto sectors. } \\
\text { Endogenous: } \\
\text { All other price, tax, technical and quantity } \\
\text { changes and slack variables. }\end{array}$ \\
\hline
\end{tabular}




\section{Box 3: False Competition: An Illustration}

An important aspect captured in the PE/GE model is false competition between the exporters. We illustrate this issue here using a hypothetical example. Let us consider SEA’s exports of Engines\&Parts to India. Aggregate import prices pimk $_{k, s}$ are weighted averages of source-specific import prices, $p m s k_{k, r, s}$, the weights $\theta_{k, r, s}^{R}$ being the value share of source-specific imports $V I W S K_{k, r, s}$ in aggregate imports (sum of VIWSK ${ }_{k, r, s}$ across sources). Using this weighting scheme and equations (11) and (13), we eliminate $\operatorname{pimk}_{k, s}, q i m k_{k, s}$, $q d k_{k, s}$ and pdk from $_{k, s}$ equation (2) for changes in source-wise imports $q x s k_{k, r, s}$. Then, we get the following expression for the own-price elasticity of source-wise imports with respect to their corresponding price:

$\frac{\text { qXsk }_{k, r, s}}{\text { pmsk }_{k, r, s}}=-\left\{\left[1-\theta_{k, r, s}^{R}\right] * \sigma_{M}+\left[1-\theta_{k, s}^{I D}\right] \theta_{k, r, s}^{R} * \sigma_{D}\right\}$

Applying equation (17) for the example considered herein, we get the following equation:

$\frac{\text { qXSk }_{\text {Eng,SEA,IND }}}{\text { pmsk }_{E n g, S E A, I N D}}=-\left\{\left[1-\theta_{E n g, S E A, I N D}^{R}\right] * \sigma_{M k}+\left[1-\theta_{E n g, I N D}^{I D}\right] \theta_{E n g, S E A, I N D}^{R} * \sigma_{D k}\right\}$

Suppose hypothetically that auto exports from SEA to India, of 500 units, comprised only engines and nothing else; similarly suppose that ROW exports only 500 units of other transport equipments and nothing else; and that India produces 5000 units of each for the local market. This would mean $\theta_{\text {Eng,SEA,IND }}^{R}=1$ and $\theta_{E n g, I N D}^{I D}=0.1$. The values for the parameters are as in the standard GTAP Data Base: $\sigma_{M k}=6.42$ and $\sigma_{D k}=3.15$. Substituting for these values in equation (18), we get an own-price elasticity as -2.8 for SEA exports of Engines to India. On the other hand, if we substitute the values at the aggregate auto sectoral level in equation (17) ( $\theta_{\text {Auto,SEA,IND }}^{R}=0.5$ and $\theta_{\text {Auto,IND }}^{I D}=0.1$, we get an own-price elasticity for SEA's auto exports to India of -4.6.

Thus, the elasticity in the aggregate auto sector shows up as more than one-and-a-half times as high as that in the engine exports, causing a false substitution effect in the GE model. This is due to the first term representing competition between SEA and ROW for the Indian market. In reality, such competition does not exist since SEA and ROW send quite different products to India. The PE-GE approach captures this insight. ${ }^{36}$

\footnotetext{
${ }^{36}$ In this example, India supplied $90 \%$ of the local consumption of all auto products, both at the aggregate and the sub-sector levels. If, in fact, these shares were different, the aggregate formula (equation 17) would
} 


\section{Box 4: Welfare Differences in PE-GE and GE models: An Illustration}

To explain the sources of welfare differences in PE-GE and GE models, we utilize equation (16). Let us consider the example of India's welfare gains herein. Rewrite the equation (16) as follows for both models:

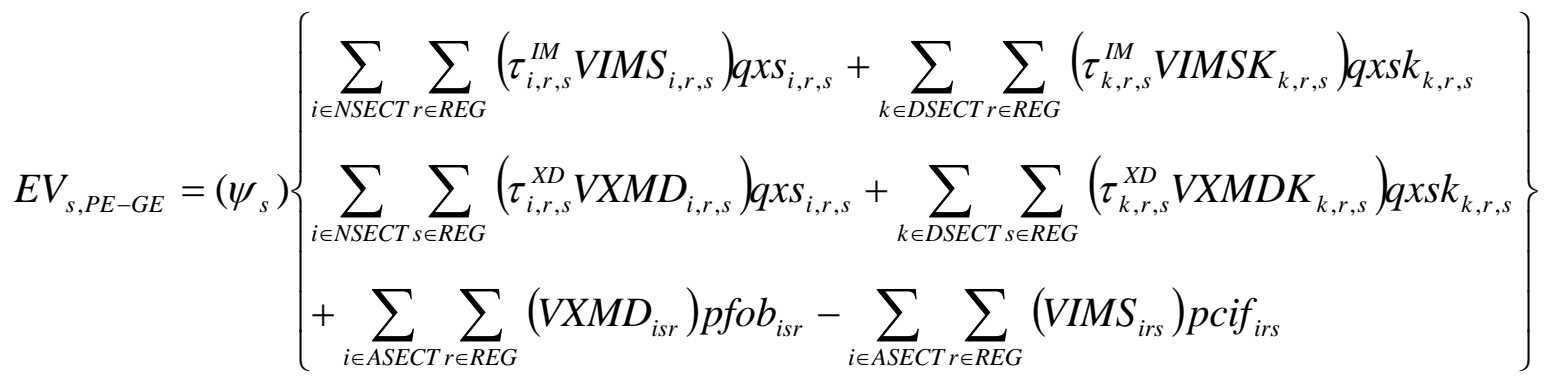

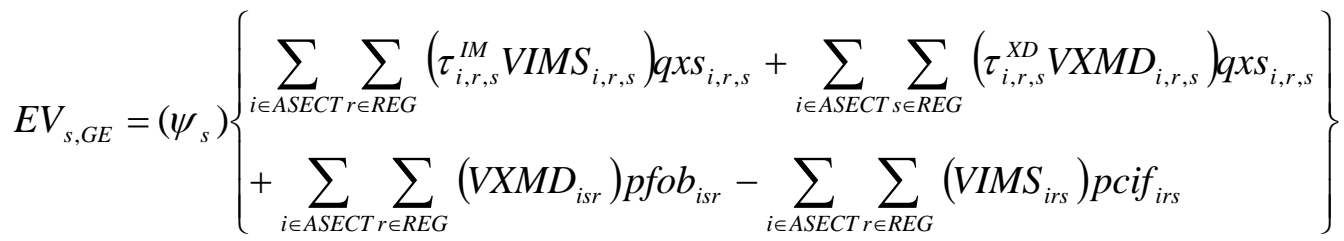

As for the AE effects, PE-GE model would show higher welfare because the quantity changes (15.1 to 362.9\%) and tariffs (7.9 to 59.7\%) of India's sub-sector-level auto imports, which influence the second term in equation (19), are much more pronounced in this model, compared to those in the GE model, where the aggregate auto tariffs are 18.6 and the quantity changes are $17.1-76.7 \%$ (see Table 3 for this aspect). Similarly, for the TOT effect, the last expression in equation (19), which turns out to be positive in both models, would be higher for PE-GE model, given that the reduction in India's CIF prices is higher in this model (around $-0.03 \%$ ) than in the GE model (around $-0.01 \%$ ).

The third, fourth and fifth terms in equation (19) are based on changes in the prices and quantitites of India's auto exports. Exports rise more in PE-GE model (3.1-4.1\%) than in GE model (2.8-2.9\%). FOB price changes are higher in PE-GE model (-0.6\%) than in GE model (-0.5\%) and this causes a slight reduction of welfare effects in PE-GE model. However, the changes in India's auto exports are quite low (quantities change 3.0-3.3\% in Auto Industry, for example) compared to those in imports by India (24.6-70.9\%, correspondingly), given that this is a simulation involving India's unilateral reduction of import tariffs. Export effects are further subdued by the fact that India's total auto imports (US\$ 2.6 billion) far exceed its total auto exports (US\$ 1.2 billion). In short, the more pronounced changes in prices and quantities captured

again overestimate the degree of import-domestic substitution, giving rise to another type of "false competition". 
by the PE-GE model, coupled with the lower size and changes in the exports that could have otherwise reduced some welfare, get translated into higher welfare gains compared to the GE model. Therefore, all these welfare differences are well-explained by the differences in the model structures and the finer details of disaggregate data used by the PE-GE model. 


\section{Tables}

Table 1: Initial levels of Tariffs and import shares in Indian Auto sector ${ }^{37}$

\begin{tabular}{|c|c|c|c|c|c|c|c|c|c|}
\hline & \multicolumn{2}{|c|}{$\begin{array}{c}\text { India's Tariff } \\
\text { Rates of } \\
\text { Imports from: }\end{array}$} & $\begin{array}{c}\text { Share of } \\
\text { Imports } \\
\text { of Sub-sectors in } \\
\text { India's Auto } \\
\text { Imports from: }\end{array}$ & \multicolumn{2}{c|}{$\begin{array}{c}\text { Import-weighted } \\
\text { Tariff Average }\end{array}$} & \multicolumn{3}{|c|}{$\begin{array}{c}\text { Shares of India's } \\
\text { Imports in Each } \\
\text { Sub-sector in India's } \\
\text { Total Imports, from: }\end{array}$} \\
\hline Region $\rightarrow$ & SEA & ROW & SEA & ROW & SEA & ROW & SEA & ROW & Total \\
\hline Motorcycles & 59.7 & 48.2 & 0.001 & $<0.001$ & 0.060 & 0.008 & 0.779 & 0.221 & 1 \\
\hline McycleParts & 19.8 & 16.1 & 0.047 & 0.002 & 0.929 & 0.023 & 0.949 & 0.051 & 1 \\
\hline Automobiles & 52.0 & 33.6 & 0.031 & 0.062 & 1.616 & 2.066 & 0.241 & 0.759 & 1 \\
\hline EnginesParts & 19.8 & 16.1 & 0.593 & 0.206 & 11.74 & 3.307 & 0.622 & 0.378 & 1 \\
\hline OtherTrans & 12.9 & 7.9 & 0.328 & 0.731 & 4.216 & 5.794 & 0.206 & 0.794 & 1 \\
\hline \multicolumn{2}{|c|}{ Total } & & 1 & 1 & 18.6 & 11.2 & 0.371 & 0.629 & 1 \\
\hline
\end{tabular}

Table 2: India's Import-changes shown by PE-GE, GE and PE models (\% Changes post-simulations)

\begin{tabular}{|c|c|c|c|c|c|c|c|}
\hline & \multicolumn{5}{|c|}{ Sub-sectors in Auto Industry } & \multicolumn{2}{|c|}{ Aggregate Auto } \\
\hline & $\begin{array}{l}\text { Motor- } \\
\text { cycles }\end{array}$ & $\begin{array}{l}\text { Mcycle } \\
\text { Parts }\end{array}$ & $\begin{array}{c}\text { Auto } \\
\text { Mobiles }\end{array}$ & $\begin{array}{l}\text { Engines } \\
\text { \& Parts }\end{array}$ & $\begin{array}{l}\text { Other } \\
\text { Trans }\end{array}$ & $\begin{array}{c}\text { Results from } \\
\text { PE-GE \& PE models }\end{array}$ & $\begin{array}{r}\text { Results from } \\
\text { GE model }\end{array}$ \\
\hline \multicolumn{8}{|l|}{ Imports from $R O W$} \\
\hline \multicolumn{8}{|l|}{ Results from PE-GE Model } \\
\hline Domestic Penetration Effect & 201.9 & 34.3 & 113.1 & 44.1 & 20.5 & 33.3 & 28.0 \\
\hline Substitution Effect among sources & -16.0 & -11.5 & -13.5 & -9.0 & -5.4 & -12.0 & -10.9 \\
\hline Total Change in Imports by India (qxsk) & 185.9 & 22.8 & 99.6 & 35.1 & 15.1 & 24.5 & 17.1 \\
\hline \multicolumn{8}{|l|}{ Results from PE Model } \\
\hline Domestic Penetration Effect & 156.5 & 19.5 & 85.0 & 27.3 & 52.3 & 25.7 & 28.0 \\
\hline Substitution Effect among sources & -15.5 & -9.5 & -13.0 & -8.5 & -50.3 & N.A. & -10.9 \\
\hline Total Change in Imports by India (qxsk) & 141.0 & 10.0 & 72.0 & 18.8 & 1.9 & 9.7 & 17.1 \\
\hline \multicolumn{8}{|l|}{ Imports from $S E A$} \\
\hline \multicolumn{8}{|l|}{ Results from PE-GE Model } \\
\hline Domestic Penetration Effect & 356.6 & 49.4 & 285.4 & 58.6 & 28.5 & 52.1 & 49.9 \\
\hline Substitution Effect among sources & 6.3 & 0.8 & 70.4 & 6.7 & 24.9 & 9.5 & 26.8 \\
\hline Total Change in Imports by India (qxsk) & 362.9 & 50.2 & 355.8 & 65.2 & 53.4 & 70.0 & 76.7 \\
\hline \multicolumn{8}{|l|}{ Results from PE Model } \\
\hline Domestic Penetration Effect & 282.6 & 33.6 & 222.5 & 38.5 & 7.5 & 25.7 & 49.9 \\
\hline Substitution Effect among sources & 6.3 & 0.8 & 69.4 & 6.6 & 28.0 & N.A. & 26.8 \\
\hline Total Change in Imports by India (qxsk) & 288.9 & 34.4 & 291.9 & 45.1 & 35.5 & 49.3 & 76.7 \\
\hline
\end{tabular}

Note: Decomposition of qxs and qxsk into domestic penetration and substitution effects was done by adjusting the actual output from GTAP's AnalyseGE (Pearson et. al, 2002), to ensure that these components sum to actual totals of qxs and qxsk. The original components do not sum up to actual qxs/qxsk, thanks to the non-linear solution procedure of Gragg. ${ }^{38}$

\footnotetext{
${ }^{37}$ Since the third 2-column panel comprises the products of corresponding elements of the first two2column panels, the two totals in this panel are actually import-weighted totals of the two columns in the first 2-column panel. Therefore they are, in effect, average tariff rates in Indian auto sector.

${ }^{38}$ We do not show SSA results in this table, because of this adjustment, for a better presentation of the results. Table 3 and 4 show some SSA results.
} 
Table 3: Changes in Prices and Quantities in Inda’s Auto Sector (in \% Changes Post-simulation)

\begin{tabular}{|c|c|c|c|c|c|c|c|c|}
\hline \multirow[t]{2}{*}{ Sub-Sectors } & \multicolumn{2}{|c|}{$\begin{array}{l}\text { India's Imports } \\
\text { From }(q \times s k):\end{array}$} & \multirow{2}{*}{$\begin{array}{l}\text { India's } \\
\text { Imports } \\
\text { (qimk) }\end{array}$} & \multirow{2}{*}{$\begin{array}{l}\text { Import } \\
\text { Prices } \\
\text { (pimk) }\end{array}$} & \multirow{2}{*}{$\begin{array}{c}\text { Domestic } \\
\text { Prices } \\
(p d k)\end{array}$} & \multirow{2}{*}{$\begin{array}{c}\text { Market } \\
\text { Prices } \\
\text { (pmk) }\end{array}$} & \multicolumn{2}{|c|}{$\begin{array}{l}\text { Import Prices } \\
\text { From (pmsk): }\end{array}$} \\
\hline & SEA & ROW & & & & & SEA & ROW \\
\hline \multicolumn{9}{|l|}{ Auto: PE-GE } \\
\hline Lower Bound & 67.3 & 24.0 & 40.5 & -12.9 & -2.3 & -0.5 & -16.3 & -10.6 \\
\hline Upper Bound & 72.5 & 24.8 & 43.4 & -12.8 & -2.3 & -0.5 & -16.2 & -10.5 \\
\hline Auto: GE & 76.7 & 17.1 & 38.7 & -12.4 & N.A. & -0.4 & -15.6 & -10.1 \\
\hline Auto: PE & 49.3 & 9.7 & 24.0 & -20.5 & -12.8 & -12.1 & -16.7 & -11.0 \\
\hline \multicolumn{9}{|l|}{ PE-GE } \\
\hline Motorcycles & 362.9 & 185.9 & 322.7 & -36.5 & 1.0 & 1.1 & -37.4 & -32.5 \\
\hline MCycleparts & 50.2 & 22.8 & 48.7 & -16.4 & -5.5 & -2 & -16.5 & -13.8 \\
\hline Automobiles & 355.8 & 99.6 & 158.4 & -28.1 & -2.8 & -0.7 & -34.2 & -25.1 \\
\hline EnginesParts & 65.2 & 35.1 & 53.7 & -15.5 & -3.2 & -0.9 & -16.5 & -13.8 \\
\hline Other'Trans & 53.4 & 15.1 & 22.9 & -8.3 & -1.9 & -0.3 & -11.4 & -7.3 \\
\hline \multicolumn{9}{|l|}{ PE } \\
\hline Motorcycles & 288.9 & 141.0 & 255.3 & -36.8 & -5.4 & -5.3 & -37.7 & -32.8 \\
\hline MCycleparts & 34.4 & 10.0 & 33.1 & -16.8 & -9.3 & -7.1 & -17.0 & -14.3 \\
\hline Automobiles & 291.9 & 72.0 & 122.4 & -28.5 & -8.0 & -6.5 & -34.4 & -25.6 \\
\hline Engines Parts & 45.1 & 18.8 & 35.1 & -16.0 & -7.8 & -6.4 & -17.0 & -14.3 \\
\hline Other'Trans & 35.5 & 1.9 & 8.7 & -8.8 & -6.3 & -5.7 & -11.9 & -7.9 \\
\hline
\end{tabular}

Note: The Lower and Upper Bounds for the results from the PE-GE model are calculated at 95\% Confidence Interval, using Chebyshev's inequality, based on a systematic sensitivity analysis that varied the elasticity of substitution among sub-sectors between 0 and 1 and elasticity of transformation among them between -4 and 0 .

Table 4. Welfare Decomposition: An Overall Comparison of GE and PE-GE Models

\begin{tabular}{|c|c|c|c|c|c|c|c|c|}
\hline & \multicolumn{2}{|c|}{$\begin{array}{c}\text { Allocative } \\
\text { Efficiency }\end{array}$} & \multicolumn{2}{c|}{ Terms of Trade } & \multicolumn{2}{c|}{ Investment-Savings } & \multicolumn{2}{c|}{ Total Welfare Gain } \\
\hline & GE & PE-GE & GE & PE-GE & GE & PE-GE & GE & PE-GE \\
\hline SEA & 4.7 & $(5.7,8.3)$ & 75.1 & $(64.4,70.3)$ & -11.6 & $(-11.7,-11.3)$ & 67.8 & $(58.4,67.3)$ \\
\hline IND & 11.3 & $(25.7,27.5)$ & -96.2 & $(-101.6,-101.3)$ & 6.2 & $(4.2,4.2)$ & -80.9 & $(-71.7,-69.6)$ \\
\hline ROW & 15.9 & $(20.9,22.8)$ & 21 & $(31.1,37.0)$ & 5.4 & $(7.2,7.5)$ & 44.9 & $(59.1,67.3)$ \\
\hline Total & 31.9 & $(52.3,58.6)$ & 0 & $(-6.1,6.0)$ & 0 & $(-0.4,0.4)$ & 31.8 & $(45.8,65.0)$ \\
\hline
\end{tabular}

Note: All figures in Tables 4 and 5 are in US\$ Million; for PE-GE Allocative Efficiency and Total Welfare Gain results, we show the range between lower and upper bounds within the parentheses, as explained in the note in Table 3 . We do not show the range for the terms of trade, as their total is always zero. 
Table 5. Import-tax-related Allocative Efficiency Effects for India’s Auto Imports at Sub-sector Level

\begin{tabular}{|c|c|c|c|c|c|c|c|c|}
\hline & \multicolumn{3}{|c|}{ Imports from SEA } & \multicolumn{3}{c|}{ Imports from ROW } & \multicolumn{2}{c|}{ All Auto Imports by IND } \\
\cline { 2 - 9 } Sub-sector & $\begin{array}{c}\text { Base } \\
\text { Tariff rate }\end{array}$ & $\begin{array}{c}\text { Change in } \\
\text { Imports }\end{array}$ & $\begin{array}{c}\text { Change in } \\
\text { Welfare }\end{array}$ & $\begin{array}{c}\text { Base } \\
\text { Tariff rate }\end{array}$ & $\begin{array}{c}\text { Change in } \\
\text { Imports }\end{array}$ & $\begin{array}{c}\text { Change in } \\
\text { Welfare }\end{array}$ & $\begin{array}{c}\text { Change in } \\
\text { Imports }\end{array}$ & $\begin{array}{c}\text { Change in } \\
\text { Welfare }\end{array}$ \\
\hline Motorcycles & 59.7 & 2.8 & 0.6 & 48.2 & 0.4 & 0.1 & 3.2 & 0.7 \\
\hline MCycleparts & 19.8 & 18.3 & 1.7 & 16.1 & 0.5 & 0.0 & 18.7 & 1.8 \\
\hline Automobiles & 52.0 & 85.9 & 17 & 33.6 & 85.7 & 13.2 & 171.6 & 30.2 \\
\hline EnginesParts & 19.8 & 300.3 & 27.6 & 16.1 & 101.0 & 8.0 & 401.3 & 35.6 \\
\hline OtherTrans & 12.9 & 136.0 & 8.3 & 7.9 & 154.2 & 6.3 & 290.3 & 14.5 \\
\hline Auto: PEGE & $\mathbf{1 8 . 6}$ & $\mathbf{5 4 3 . 4}$ & $\mathbf{( 5 2 . 4 , 5 6 . 1}$ & $\mathbf{1 1 . 2}$ & $\mathbf{3 4 1 . 8}$ & $\mathbf{( 2 6 . 9 , 2 8 . 3 )}$ & $\mathbf{8 8 5 . 2}$ & $\mathbf{( 7 9 . 3 , 8 4 . 4 )}$ \\
\hline Auto: GE & $\mathbf{1 8 . 6}$ & $\mathbf{5 9 5 . 2}$ & $\mathbf{5 0 . 7}$ & $\mathbf{1 1 . 2}$ & $\mathbf{2 3 8 . 7}$ & $\mathbf{1 4 . 2}$ & $\mathbf{8 3 3 . 9}$ & $\mathbf{6 4 . 9}$ \\
\hline
\end{tabular}

Note: All figures except the tariff rates are in US\$ Million; for PE-GE Welfare Change results, we show the range between lower and upper bounds within the parentheses as explained in the note in Table 3. 